\title{
Potassium Currents Responsible for Inward and Outward Rectification in Rat Neostriatal Spiny Projection Neurons
}

\author{
Eric S. Nisenbaum and Charles J. Wilson \\ Department of Anatomy and Neurobiology, College of Medicine, University of Tennessee-Memphis, Memphis, \\ Tennessee 38163
}

\begin{abstract}
Many of the nonlinear membrane properties displayed by neostriatal spiny projection neurons are conferred by their voltage-gated potassium $\left(\mathrm{K}^{+}\right)$currents, including an inwardly rectifying current $\left(I_{\mathrm{Kir}}\right)$, fast $\left(I_{\mathrm{At}}\right)$, and slowly $\left(I_{\mathrm{As}}\right)$-inactivating $A$-currents, and a slow, noninactivating current. The relative contribution of these $K^{+}$currents to the pronounced inward and outward rectification of the currentvoltage $(1-\eta)$ relationship of spiny neurons was investigated in a neostriatal slice preparation. Manipulation of the equilibrium potential for $K^{+}\left(E_{\kappa}\right)$ showed that the voltage dependence of activation of inward rectification was identical to that of $I_{\mathrm{Kir}}$ In addition, application of barium (100 $\mu \mathrm{M})$, which is known to reduce $I_{\mathrm{kir}}$ in a time- and voltagedependent manner, had equivalent effects on inward rectification. Subsequent application of cesium (3 $\mathrm{mm}$ ) or tetraethylammonium (TEA, $25 \mathrm{~mm}$ ) blocked inward rectification in a solely voltage-dependent fashion consistent with the action of these blockers on $I_{\text {Kir }}$.

Administration of 4-aminopyridine (4-AP, $100 \mu \mathrm{M}$ ) at concentrations that selectively depress $I_{A s}$, reduced outward rectification of spiny neurons at subthreshold membrane potentials. Higher concentrations of 4-AP (2 $\mathrm{mM})$, which block both $I_{\mathrm{As}}$ and $I_{\mathrm{Ar}}$, revealed an early transient overshoot in voltage deflections at potentials near spike threshold, but rectification persisted at the end of the responses. The transient overshoot and the residual rectification were eliminated by TEA ( $25 \mathrm{~mm}$ ), a blocker of the slow, noninactivating $K$ current. Collectively, these results indicate that all three depolarization-activated $K$ currents contribute to outward rectification at different times and membrane potentials defined by their voltage dependence of activation and kinetics of inactivation.
\end{abstract}

The spontaneous activity of neostriatal spiny neurons recorded in intact animals is characterized by sustained and limited shifts in membrane potential from relatively hyperpolarized potentials to depolarized potentials near spike threshold. The present data suggest that the hyperpolarized state is determined principally by $I_{\text {Kir }}$ and the limits on the depolarized state are defined by $I_{A B}, I_{A s}$, and the noninactivating current. These outward $K$ currents also are hy-

\footnotetext{
Received Oc1. 12. 1994: revised Dec. 28, 19943; accepted Jan. 3. 1994

We thank Dr. Anthony E. Kincaid for his assistance with the photography. This work was supported by the Office of Naval Research Grant N00014-92$\mathrm{J}-1113$ and USPHS Grant NS26473.

Correspondence should be addressed to Dr. Charles J. Wilson, Department of Anatomy and Neurobiology, University of Tennessee. Memphis, 855 Monroe Avenue, Memphis, TN 38163.

Copyright $\bigcirc 1995$ Society for Neuroscience (270-6474/95/154449-15\$05.00/0
}

pothesized to govern the spike discharge characteristics once the depolarized state has been reached.

[Key words: potassium currents, A-currents, inward rectification, outward rectification, neostriatum, slice preparation]

Since the first intracellular recordings were made from neostriatal spiny projection neurons either in vivo or in vitro, investigators noted that the voltage deflections evoked by intracellular current pulses displayed rectification in the subthreshold region of membrane potentials (Sugimori et al., 1978; Wilson et al., 1983; Kita et al., 1984). The $I-V$ relationship of spiny neurons is normally characterized by a marked inward rectification in both the hyperpolarizing and depolarizing directions from the resting potential. In response to hyperpolarization from rest, inward rectification is defined as an increase in membrane conductance that is manifested as a saturation in the amplitude of hyperpolarizing voltage responses as a function of increasing current intensity. In response to depolarization from rest, inward rectification is defined as a decrease in membrane conductance that is expressed as a supralinear increase in the amplitude of depolarizing voltage responses as a function of increasing current intensity (Kita et al., 1984; Bargas et al., 1989; Kawaguchi et al., 1989; Nisenbaum et al., 1994b). However, when inward $\mathrm{Na}^{+}$and $\mathrm{Ca}^{2}$ currents are blocked, a prominent outward rectification is evident at depolarized membrane potentials near the threshold for spike discharge (Nisenbaum et al., 1994b). Outward rectification is characterized by an increase in membrane conductance and is revealed as a saturation in the amplitude of depolarizing voltage responses as a function of increasing current intensity. Thus, in the absence of $\mathrm{Na}^{+}$and $\mathrm{Ca}^{3+}$ currents, the $I-V$ relationship of spiny neurons is dominated by inward rectification in response to hyperpolarization and small depolarizations, and outward rectification in response to large depolarizations (Nisenbaum et al., 1994b).

Previous studies have shown that many cell types exhibit rapid inward rectification in response to hyperpolarization. In these cells, this property is produced by an inwardly rectifying or anomalous $\mathrm{K}^{+}$current $\left(I_{\text {Kir }}\right)$ (Katz, 1949; Kandel and Tauc, 1966; Hagiwara and Takahashi, 1974; Hagiwara et al., 1976; Constanti and Galvan, 1983; Uchimura et al., 1989). $I_{\text {Kir }}$ has a unique voltage dependence in that its magnitude depends on the difference between the membrane potential $\left(V_{m}\right)$ and $E_{\mathrm{K}}\left(V_{m}-E_{\mathrm{K}}\right)(\mathrm{Hag}-$ iwara and Yoshii, 1979; Leech and Stanfield, 1981). In addition, $I_{\text {Kir }}$ activates rapidly and shows little inactivation (Hagiwara et al., 1976). $I_{\mathrm{Kir}}$ can be blocked in a time- and voltage-dependent manner by low concentrations of extracellular barium $(0.01-0.1$ mM) (Hagiwara et al., 1978; Standen and Stanfield, 1978; Uchi- 
mura et al., 1989), and in a predominantly voltage-dependent manner by higher concentrations of cesium (2-10 mM) and TEA (> $20 \mathrm{~mm}$ ) (Gay and Stanfield, 1977; Uchimura et al., 1989). For neurons of the nucleus accumbens, $I_{\mathrm{Kir}}$ has been estimated to account for approximately $50 \%$ of the resting conductance, indicating that this current contributes significantly to the resting membrane potential of these neurons (Uchimura et al., 1989). Voltage-clamp recordings from neostriatal spiny cells have shown that their voltage-current relationship is characterized by a marked inward rectification in response to hyperpolarizing voltage ramps (Jiang and North, 1991). Thus, these data suggest that $I_{\mathrm{Kir}}$ is responsible for inward rectification and contributes to the resting potential of spiny projection neurons.

The outward rectification of neostriatal spiny neurons is postulated to depend upon several distinct depolarization-activated $\mathrm{K} *$ currents. Voltage-clamp recordings from neostriatal neurons have identified at least three types of outward $\mathrm{K}^{+}$currents, including two types of transient currents termed A-currents, and a relatively noninactivating current (Surmeier et al., 1991, 1992; Nisenbaum et al., 1994a). The two A-currents can be distinguished on the basis of differences in their voltage dependence of activation, kinetics of inactivation, and sensitivity to blockade by toxins. The fast-inactivating A-current $\left(I_{\mathrm{At}}\right)$ is available at potentials at or above spike threshold $(\sim-40 \mathrm{mV})$, inactivates rapidly within $50-100 \mathrm{msec}$, and is blocked by relatively high concentrations of 4-AP $\left(\mathrm{IC}_{5 i}=2 \mathrm{~mm}\right.$ ) (Surmeier et al., 1994). In contrast, the slowly inactivating A-current $\left(I_{\mathrm{AS}}\right)$ is available at subthreshold membrane potentials $(\sim-60 \mathrm{mV})$, inactivates over hundreds of milliseconds to seconds, and is selectively blocked by low concentrations of 4-AP $\left(\mathrm{IC}_{50}=100 \mu \mathrm{M}\right)$ (Surmeier et al., 1991, 1994). Unlike cither of these A-currents, the noninactivating current is available at the most hyperpolarized potentials $(\sim-75 \mathrm{mV})$, shows little inactivation, and is blocked by TEA $\left(\mathrm{IC}_{50}=5 \mathrm{~mm}\right)$ (Nisenbaum et al., 1994a). On the basis of differences in their voltage-dependent and kinetic properties, these three depolarization-activated $\mathrm{K}^{+}$currents are predicted to make distinct contributions to the outward rectification of spiny neurons.

The present experiments have investigated the contribution of $I_{\mathrm{Kir}}$ to inward rectification and the depolarization-activated $\mathrm{K}^{+}$ currents to outward rectification in identified spiny projection neurons in a neostriatal slice preparation. Using the information on the pharmacological properties of $I_{\mathrm{Kir}}$ and its peculiar dependence on $E_{\mathrm{K}}$, the contribution of this current to the inward rectification, resting membrane potential, and low input resistance of spiny neurons was assessed. Similarly, on the basis of the distinct pharmacological sensitivities of $I_{\mathrm{Al}}, I_{\mathrm{A} S}$, and the noni nactivating current to 4-AP and TEA, the role of these individual currents in limiting the membrane potential in the face of depolarization was evaluated. The results are discussed within the context of the manner in which these currents govern the subthreshold behavior and spontaneous episodic firing of spiny neurons observed in intact animals.

\section{Materials and Methods}

In vitro slice preparation. All experimental procedures were conducted in accordance with the Guide for the Care and Use of Laboratory Animals published by the U.S. Public Health Service, and all protocols were approved by the Institutional Animal Care and Use Committee of the University of Tennessee-Memphis. The animals $(N=58)$ used in these experiments were male, Sprague-Dawley albino rats (Harlan Laboratories, Indianapolis, IN) weighing 150-300 gm. All animals were deeply anesthetized with a mixture of ketamine and xylazine $(30 \mathrm{mg} /$ kg, i.p.) and decapitated. Their brains were removed rapidly from the skull and immersed in a $2^{\circ} \mathrm{C}$ solution of physiological saline. This control saline solution contained (concentrations in mM) $\mathrm{NaCl} 125.0, \mathrm{KCl}$ $3.0, \mathrm{MgCl}_{2} 1.5, \mathrm{Na}_{2} \mathrm{PO}_{4} 1.25, \mathrm{CaCl}_{2} 2.0, \mathrm{NaHCO}, 26.0$, glucose 10.0 and was bubbled with a $95 \% \mathrm{O}_{2}: 5 \% \mathrm{CO}_{2}$ mixture to achieve a $\mathrm{pH}$ value of 7.3-7.4. The osmolarity of the saline solution was adjusted to 300 $\pm 5 \mathrm{mOsm} /$ iter. The brains were hemisected and blocked caudally at the level of the hippocampus and along the ventral surface of each hemisphere. Each block of tissue then was mounted onto a plastic stage and placed into a slicing chamber. Using a Vibroslice (Campden Instruments Ltd.), 300-400 $\mu \mathrm{m}$ thick sections were cut at approximately a $30^{\circ}$ angle relative to the horizontal plane through the dorsoventral extent of the neostriatum (Arbuthnott et al., 1985; Nisenbaum et al., 1988; Kawaguchi et al., 1989). Each slice of tissue contained the anterodorsal region of the neostriatum. the adjacent anterior white matter. and portions of the anterior cortex. Slices then were incubated in a holding chamber containing continuously oxygenated saline solution and maintained at room temperature for $1-2 \mathrm{hr}$ prior to recording.

Electrophysiological procedures. After the incubation period, single slices were transferred to a Plexiglas recording chamber $(0.5 \mathrm{ml}$ volume) submerged beneath the fluid surface, and superfused continuously with oxygenated physiological saline preheated to approximately $33^{\circ} \mathrm{C}$. The flow rate of the saline solution was adjusted to $2-3 \mathrm{ml} / \mathrm{min}$. Intracellular recordings were made from neostriatal neurons using glass microelectrodes (electrode resistance $=60-130 \mathrm{M} \Omega$ ) pulled from $1 \mathrm{~mm}$ capillary tubing (World Precision Instruments, Inc.. Sarasota, FL) using a horizontal electrode puller (Sutter Instrument Co.). Electrodes were filled with $1-4 \mathrm{M}$ potassium acetate and 2-4\% biocytin (Sigma. St. Louis, MO). When possible, cells were filled with biocytin by injecting depolarizing current pulses $0.5-1.5 \mathrm{nA}$ in amplitude and $300 \mathrm{msec}$ in duration at a rate of $5-10 \mathrm{~Hz}$ for $5-60 \mathrm{~min}$. At the end of an experiment. slices containing biocytin-injected neurons were submerged in $4 \%$ paraformaldehyde in phosphate-buffered saline (PBS) and stored at $4^{\circ} \mathrm{C}$ for subsequent tissue processing.

Histological procedures. Processing of slices containing biocytin-injected neurons followed previously published procedures (Horikawa and Armstrong, 1988). Prior to sectioning, the cortex was removed and the slice was embedded in $5 \%$ agar. An agar block was mounted onto a glass slide and placed into a slicing chamber. Sections $50-75 \mu \mathrm{m}$ in thickness were cut using a Vibratome (TPI, Inc.) and placed into a Petri dish containing PBS and $3 \% \mathrm{H}_{2} \mathrm{O}_{2}$. The sections then were transferred to test tubes containing a $0.5 \%$ solution of Triton $\mathrm{X}-100$ in PBS for 30 min. Subsequently, the sections were incubated in an avidin biotin HRP complex (ABC solution, Vector Laboratories, Burlingame, CA) using a dilution of 1:200 for $24 \mathrm{hr}$. After rinsing, the sections were reacted with diaminobenzidine tetrahydrochloride $(0.05 \%)$ containing $\mathrm{H}_{2} \mathrm{O}_{2}(0.003 \%)$ and $\mathrm{NiCl}(0.06 \%)$ and mounted onto glass slides.

Measurement of input resistance and membrane time constant. Measurement of input resistance requires that the effective membrane resistance be independent of membrane potential and time (Rall, 1977). However, it is well known that the membranes of neostriatal spiny neurons like many other neurons exhibit nonlinearities active at their resting potential, and so violate this requirement (Kita et al.. 1984: Calabresi et al., 1987b; Bargas et al., 1989; Kawaguchi et al., 1989; Nisenbaum et al., 1994b). The voltage dependence of membrane resistance produces a nonlinear voltage-current curve over the range of physiologically relevant membrane potentials. A related problem is the ramp potential evoked by depolarizing current pulses that precludes the existence of a steady-state $I-V$ relationship over a large portion of the current range (Kita et al., 1984; Bargas et al., 1989; Kawaguchi et al., 1989; Nisenbaum et al., 1994b). Thus, in order to obtain an estimate of input resistance at any one voltage, we have adopted an arbitrary definition. Input resistance was estimated by (1) measuring the membrane potential achieved at the end of $400 \mathrm{msec} 0.2 \mathrm{nA}$ depolarizing and hyperpolarizing current pulses, (2) subtracting these two values, and (3) dividing by the difference in current $(0.4 \mathrm{nA})$. The voltage deflections produced by the small depolarizing current pulse did not evoke a ramp depolarization so the membrane potential achicved a steady state.

The confounds described above also apply to measurements of the time constant $(\tau=R C$ ) of neostriatal cell membranes. Generally, the time constant is measured by making a log plot of the voltage transient evoked by a small amplitude hyperpolarizing current and fitting a line to the linear portion of the response. However, any membrane nonlinearities resulting from voltage-gated conductances will preclude measurement of the membrane time constant of neostriatal neurons. In order 
to determine the time constant of the membrane, the $I-V$ relationship of these cells would have to be linear. As it is not under normal conditions, it is more accurate then to describe such measurements as being of the apparent membrane time constant. The apparent membrane time constant was determined using the voltage transient evoked by a -0.2 nA current pulse $400 \mathrm{msec}$ in duration. The apparent membrane time constant was calculated by (1) subtracting the membrane potential at each time point from the maximum potential of the voltage transient, (2) dividing this quantity by the maximum potential, (3) plotting this value on a logarithmic axis as a function of time after the onset of the current pulse, and (4) fitting a line to the linear portion of the plotted points.

Drugs. Drugs used in these experiments included 4-aminopyridine (4-AP, 0.3-2 mm; Sigma, St. Louis MO), barium chloride (barium, 100 $\mu \mathrm{M}$; Sigma), cadmium chloride (cadmium, $400 \mu \mathrm{M}$; Sigma), cesium chloride (cesium, $3 \mathrm{~mm}$; Sigma), tetraethylammonium chloride (TEA 10-25 mM, Sigma) and tetrodotoxin (TTX, $1 \mu \mathrm{m}$; Research Biochemicals Inc., Natick, MA). All drugs except TEA were made in a concentrated solution (1000:1) and then diluted to the final concentration when added directly to the superfusion media. For solutions containing TEA, the concentration of $\mathrm{NaCl}$ was reduced by the required amount to maintain normal osmolarity $(\sim 300 \mathrm{mOsm} / \mathrm{liter})$, and the desired concentration of TEA was added directly to the solution. When cadmium was used, the concentration of $\mathrm{Na}_{2} \mathrm{PO}_{4}$ was reduced to $0.3 \mathrm{~mm}$ to prevent precipitation. The rate of drug application corresponded to the rate of superfusion of the slice, which was $2-3 \mathrm{ml} / \mathrm{min}$. Drug effects were observed within 2-5 min after adding the drug to the superfusion media.

\section{Results}

\section{Cell identification}

Eighty-one neurons were recorded in these experiments, and 55 were injected intracellularly with biocytin at the end of the recording period. All of the injected neurons had the characteristic morphological features of the spiny projection neurons, which have been described in detail previously (Wilson and Groves, 1980; Kawaguchi et al., 1989, 1990) (Fig. 1A). The basic electrophysiological properties (e.g., membrane potential, input resistance, spike threshold) of all unidentified neurons were identical to those of the labeled spiny neurons. In addition, the subthreshold responses of the subpopulations of identified and unidentified neurons to the current pulse protocols were indistinguishable. More specifically, both subpopulations of neurons displayed a pronounced slowly developing depolarization in response to near-threshold depolarizing current pulses, which is a property of spiny cells (Kawaguchi et al., 1989; Nisenbaum et al., 1994b). In addition, the voltage deflections evoked by hyperpolarizing current pulses for these two groups of cells displayed a marked inward rectification (see below). Therefore, the data collected from identified and unidentified neurons were combined.

\section{The $\mathrm{I}-\mathrm{V}$ relationship of spiny neurons is characterized by inward rectification}

Subthreshold depolarizing current pulses from the resting potential evoked a slowly developing (ramp) depolarizing potential, as has been described previously (Kita et al., 1985a,b; Bargas et al., 1989; Nisenbaum et al., 1994b) (Fig. 1B). The presence of this ramp depolarization prevented the voltage transients from reaching a steady state even when the current pulse lasted for hundreds of milliseconds (Fig. 1C). When intracellular stimulation was applied so as to evoke a single-action potential discharge, the ramp potential prolonged the time to spike firing until the end of the stimulus (Fig. 1C). The ramp depolarization also contributed to the pronounced inward rectification of the $I-V$ relationship in the depolarizing direction, which was expressed as a supralinear increase in the amplitude of the depolarizing responses as a function of increasing current intensity (Fig. $1 B$, inset). The $I-V$ plots also
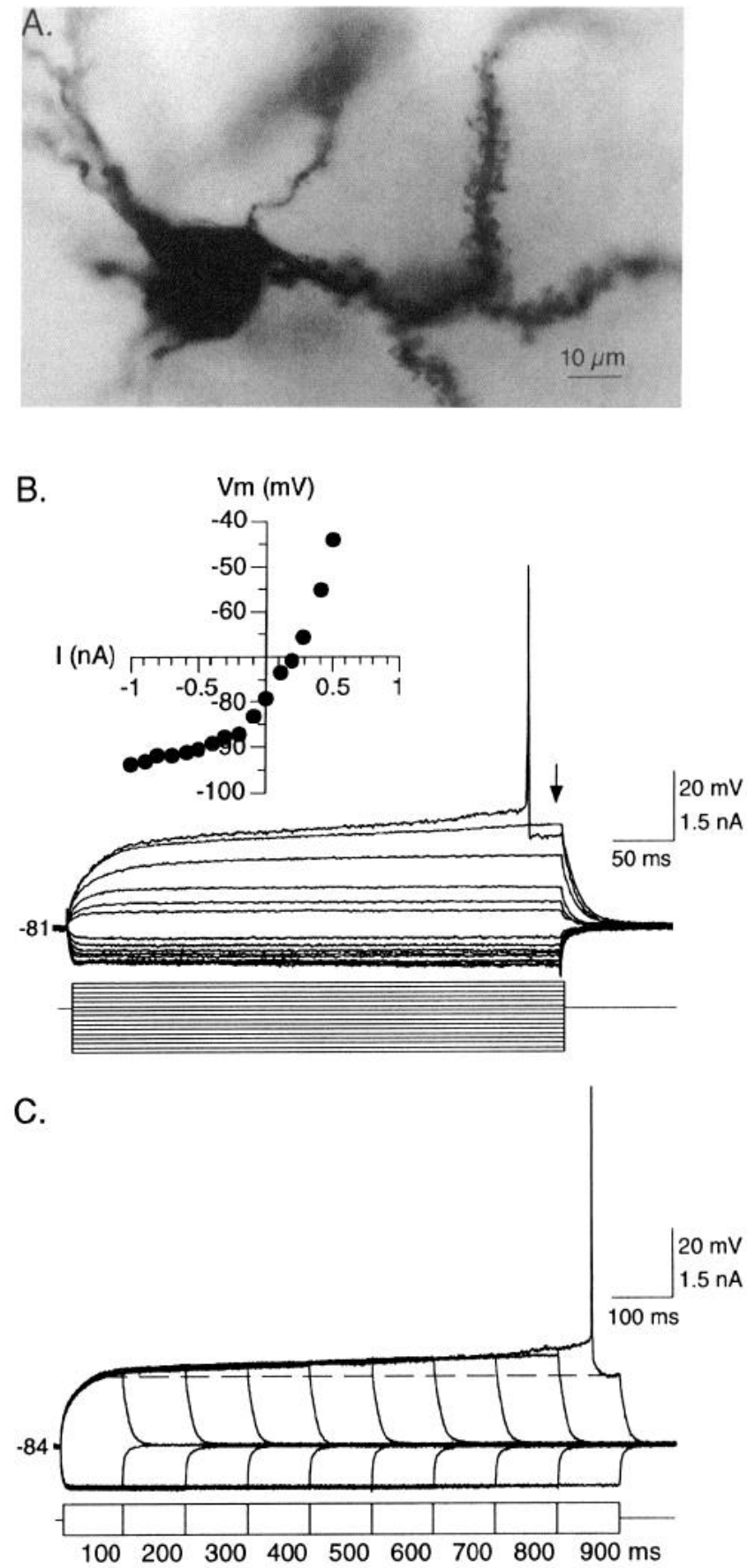

Figure 1. Depolarizing and hyperpolarizing responses of a neostriatal spiny projection neuron. $A$, An example of a biocytin-injected neostriatal spiny projection neuron is shown. This cell displays the characteristic features of spiny neurons including an aspinous soma and proximal dendrites and densely spine-covered distal dendrites. $B$, Responses of a spiny projection cell to hyperpolarizing $(0.1-1.0 \mathrm{nA})$ and depolarizing (0.1-0.6 $\mathrm{nA})$ constant current pulses $400 \mathrm{msec}$ in duration. A marked rectification of the membrane potential in response to hyperpolarizing current pulses was observed. A slowly developing ramp depolarization and long latency to spike discharge were evident using a threshold current pulse. Inset, $I-V$ plot for the responses in $B$. Each point on the plot represents the membrane potential $390 \mathrm{msec}$ (arrow) after the onset of the corresponding current pulse. $C$, Responses of a spiny neuron to constant amplitude hyperpolarizing $(-0.5 \mathrm{nA})$ and depolarizing $(0.5$ $\mathrm{nA}$ ) current pulses having durations of $100-900 \mathrm{msec}$. In response to the depolarizing pulse, the slow ramp depolarization and long delay to spike firing were readily apparent. The hyperpolarizing current pulse elicited a smaller voltage deflection that showed no change in amplitude as a function of pulse duration. 
A. $\operatorname{TTX}(1 \mu \mathrm{M})+$ cadmium $(400 \mu \mathrm{M})$

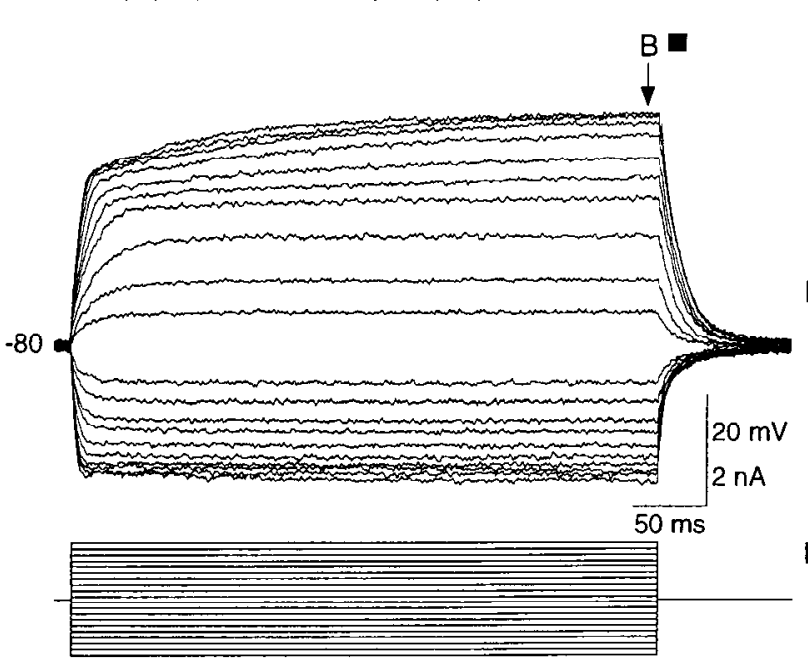

C.

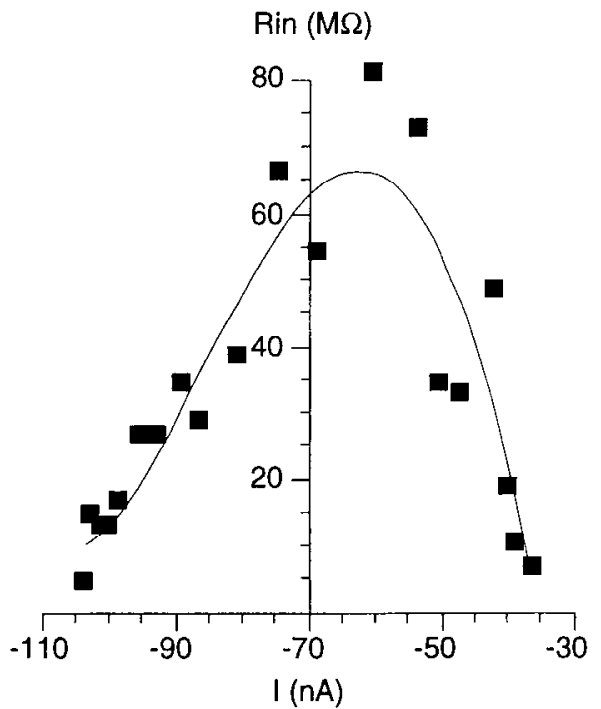

B.

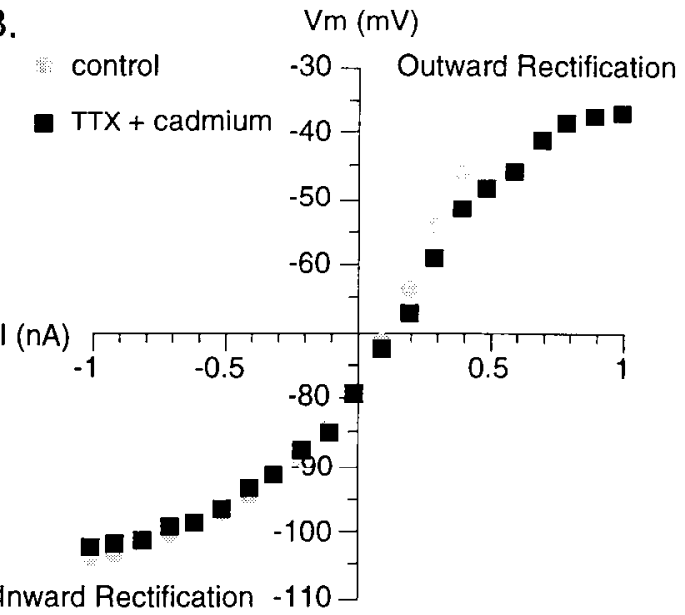

D.

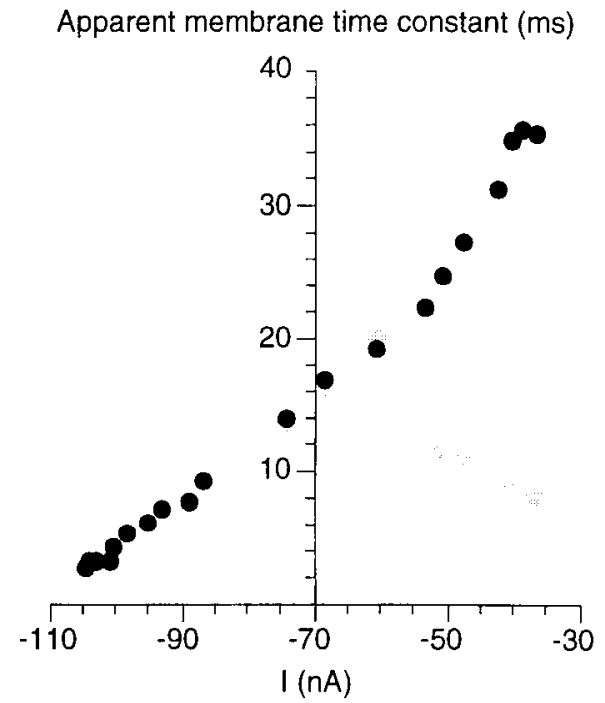

Figure 2. Inward and outward rectification of a neostriatal spiny projection neuron. $A$. Responses of a spiny neuron to hyperpolarizing and depolarizing $(-1.0$ to $1.0 \mathrm{nA})$ current pulses $(400 \mathrm{msec}$ duration) in the presence of TTX $(1 \mu \mathrm{M})$ and cadmium $(400 \mu \mathrm{M})$ are shown. The change in amplitude of the voltage deflections diminished as a function of hyperpolarizing and depolarizing current intensity, demonstrating the inward and outward rectification of the spiny cell membrane. $B$. The $I-V$ plot reflects the membrane potentials evoked by the corresponding current pulse at the time point indicated in $A$. The marked inward and outward rectification can be seen as a saturation in the plotted points in response to larger current pulses (black squares). The $I-V$ curve for the cell recorded before application of TTX and cadmium is shown for comparison (gray circles). $C$. The input resistance is plotted a as a function of membrane potential. Each point represents the slope calculated from successive pairs of adjacent points in $B$. The line was calculated by fitting the data with a fourth-order polynomial and then differentiating that polynomial. The input resistance was smallest in response to large hyperpolarizations, increased steadily in response to small hyperpolarizations and depolarizations, and then declined with greater depolarization. $D$. The apparent membrane time constant was determined for each trace in $A$. The apparent membrane time constant was lowest in response to the largest hyperpolarizations from rest, increased steadily in response to small depolarizations, then unexpectedly reached a steady state (black circles). On the basis of the plot of input resistance, the apparent membrane time constant was expected to decrease as a function of the magnitude of depolarization. This discrepancy was due to the presence of the ramp potential in the depolarizing voltage transients, which produced an artificially long apparent time constant. When measurement was restricted to the first $50 \mathrm{msec}$ of the voltage deflection, the apparent membrane time constant decreased with greater depolarization, as predicted (gray circles).

showed considerable inward rectification in response to hyperpolarization from the resting potential, which was manifested as a saturation in the amplitude of the hyperpolarizing responses as a function of increasing current intensity (Fig. $1 B$ ). Inward rectification of the voltage transients developed rapidly and persisted throughout the response, regardless of the current pulse duration (Fig. $1 C$ ). Thus, the membrane potentials of spiny neurons displayed marked inward rectification in response to either depolarizing or hyperpolarizing current pulses when recorded during control conditions (Fig. $1 B$, inset). Unlike recordings from some other cell types (Crepel and Penit-Soria, 1986; Spain et al., 1987), no cvidence of a depolarizing sag in the hyperpolarizing voltage transients was observed, nor was a rebound depolarization detected at the offset of hyperpolarizing current pulses.

\section{Blockade of inward $\mathrm{Na}^{+}$and $\mathrm{Ca}^{2+}$ currents reveals outward rectification}

When inward $\mathrm{Na}^{+}$and $\mathrm{Ca}^{2+}$ currents were blocked with TTX (1 $\mu \mathrm{M})$ and cadmium $(400 \mu \mathrm{M})$, respectively, larger current pulses could be used revealing a prominent outward rectification of the 
responses near spike threshold (Fig. $2 A, B$ ). Outward rectification of the voltage transients was revealed as a near overlap in the responses to the most depolarizing current pulses (Fig. 2A). Outward rectification in the $I-V$ plot was evidenced as a saturation in the amplitude of the depolarizing responses as a function of increasing current intensity (Fig. 2B). Inward rectification evoked by hyperpolarization was unaffected by application of TTX and cadmium (Fig. 2B). Thus, following blockade of inward $\mathrm{Na}^{+}$and $\mathrm{Ca}^{2+}$ currents, the $I-V$ relationship of spiny neurons displayed inward rectification in response to hyperpolarization and small depolarizations from rest, and outward rectification in response to large depolarizations from rest. Because these concentrations of TTX and cadmium have been shown to block all $\mathrm{Na}^{+}$and $\mathrm{Ca}^{2+}$ currents in spiny neurons (Surmeier et al., 1992; Bargas et al., 1994), only currents resistant to these toxins (e.g., $\mathrm{Cl}^{-}, \mathrm{K}^{+}$currents) will be available to contribute to inward and outward rectification. Therefore, in order to study the contribution of calcium-independent $\mathrm{K}^{+}$currents to the hyperpolarization-evoked inward rectification and depolarization-evoked outward rectification in spiny neurons, all remaining experiments were conducted in the presence of TTX and cadmium.

As a result of inward and outward rectification, the input resistance of spiny cells was greatly dependent on membrane potential. The input resistance was calculated by finding the slope between successive pairs of adjacent points in Figure $2 B$ and plotting these values as a function of membrane potential (Fig. $2 C$ ). The magnitude of input resistance was described by an inverted $\mathrm{U}$-shaped curve and was inversely related to the degree of inward and outward rectification. In response to either large hyperpolarizations or depolarizations from the resting potential $(-80 \mathrm{mV})$ when inward and outward rectification were greatest, the input resistance was small. However, in response to small depolarizations from rest, which moved the membrane potential into a voltage region between inward and outward rectification. the input resistance was maximal (Fig. 2C).

The apparent membrane time constant of spiny neurons also varied with membrane potential. The membrane time constants were extracted from log plots of the voltage transients and were plotted against membrane potential (Fig. 2D). Consistent with previous reports (Kawaguchi ct al., 1989), the membrane time constant decreased as a function of the magnitude of hyperpolarization from the resting potential. This decrease paralleled the decrease in input resistance (Fig. 2C). Similarly, the membrane time constant increased in association with input resistance in response to small depolarizations from rest. Unexpectedly, the parallel did not hold in response to the largest depolarizations. As input resistance decreased, the time constant reached a plateau (compare Fig. 2C,D, black circles). This discrepancy reflected the fact that a ramp potential remained in these large transients, which exaggerated the corresponding membrane time constant values (Fig. $2 A$ ). Thus, when measurement was restricted to the early portion of the depolarizing transients, the membrane time constant decreased in conjunction with input resistance and the presence of outward rectification (Fig. $2 A, D$, gray circles).

\section{Minimal model of inward and outward rectification in spiny neurons}

For comparison with the effects of varying $\left[\mathrm{K}^{+}\right]_{l^{\prime}}$ and $\left[\mathrm{K}^{+}\right]_{i}$ on inward and outward rectification of the $I-V$ relationship (see below), a minimal model consisting of two conductances, one inwardly rectifying (ir) and one outwardly rectifying (or), was
A

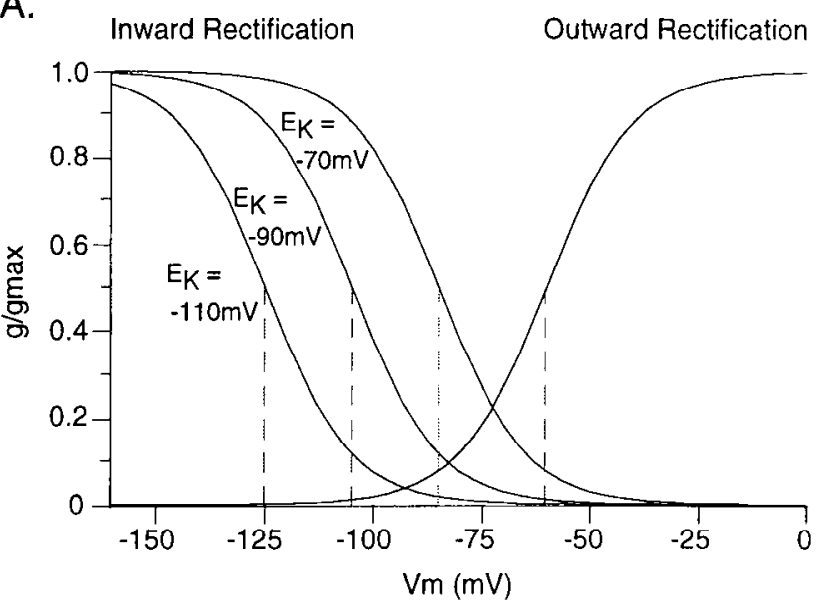

B.

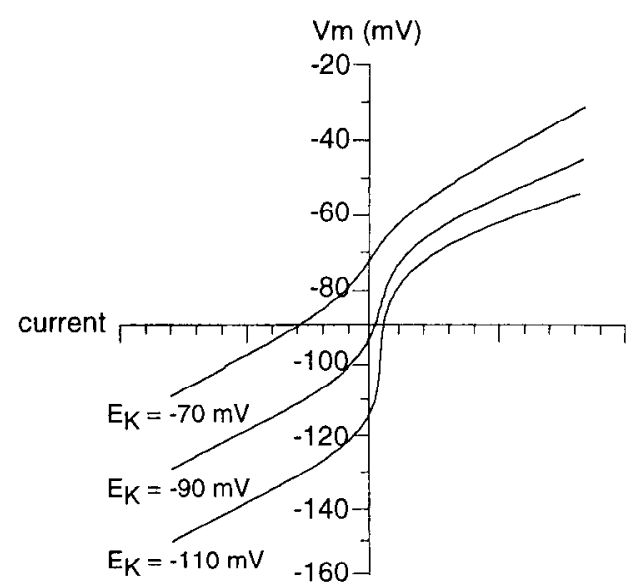

Figure 3. A minimal model of the inward and outward rectification displayed by neostriatal spiny neurons. A, A schematic shows that the model was composed of two $\mathrm{K}^{+}$currents, an inwardly and an outwardly rectifying current. The magnitude of the inwardly rectifying current at a given membrane potential depended on the $E_{\mathrm{k}}$. The steady-state activation curves for the inward rectifier when $E_{\mathrm{K}}$ is $-70,-90$, and -110 $\mathrm{mV}$ are presented. The dashed vertical lines correspond to the $V_{\mathrm{h}} \mathrm{s}$ for the inward rectifier as a function of $E_{\mathrm{K}}$, and were $-85,-105$, and -125 $\mathrm{mV}$, respectively. The magnitude of the outwardly rectifying current was solely voltage dependent and had a $V_{i}$ of $-60 \mathrm{mV}$. The $V$, for both currents was $10 \mathrm{mV} . B$. The model presented in $A$ was used to predict the $I-V$ relationship as a function of changes in $E_{\mathrm{k}}$. The plot shows that as $E_{K}$ was set to more hyperpolarized potentials, lle resting membrane potential ( 0 current level) became more hyperpolarized. Also, note that as the degree of overlap between the activation curves for the inwardly and outwardly rectifying currents diminished, the input resistance near the resting potential greatly increased.

constructed (Fig. 3A). The parameters for the inwardly rectifying conductance were similar to those used in models of $I_{\text {Kir }}$ described for starfish egg cells (Hagiwara and Takahashi, 1974) and frog skeletal muscle (Leech and Stanfield, 1981). The activation curve for the inwardly rectifying current was expressed in terms of relative conductance $\left(\mathrm{g} / \mathrm{g}_{\max }\right)$ and was defined using the Boltzmann function

$$
\mathrm{g}_{\text {(ii) }} / g_{\max (\mathrm{in}\}}-1-\left[1 /\left(1+\exp \left[\left(V_{m}-V_{t(\mathrm{ir})}\right) / V_{\text {(tin }} 1\right)\right],\right.
$$

where $V_{m}$ is the membrane potential, $V_{m \text { (ir) }}$ is the half-activation voltage and was equal to $E_{\mathrm{K}}-15 \mathrm{mV}$, and $V_{c \text { (ii }}$ is the slope factor and was held constant at $10 \mathrm{mV}$. Three different activation 
curves for the inwardly rectifying conductance were constructed in which $E_{\mathrm{K}}$ was set to $-70 \mathrm{mV},-90 \mathrm{mV}$, and $-110 \mathrm{mV}$ and $V_{h(i)}$ was equal to $-85 \mathrm{mV},-105 \mathrm{mV}$, and $-125 \mathrm{mV}$, respectively (Fig. $3 A$ ). The outwardly rectifying current also was expressed in terms of relative conductance and was defined using the Boltzmann function

$$
g_{\text {(or) }} / g_{\text {maxt(ur) }}=1 /\left(1+\exp \left[\left(V_{m}-V_{h(m)}\right) / V_{\text {c(tor }}\right]\right) \text {, }
$$

where $V_{h(w)}$, was equal to $-60 \mathrm{mV}$ and $V_{\text {c(or) }}$ was equal to $10 \mathrm{mV}$ (Fig. 3A).

When these parameters were used in computer simulations, the $I-V$ relationship varied as a function of $E_{\mathrm{K}}$ as would be predicted on the basis of the dependence of $I_{\mathrm{Kir}}$ on $E_{\mathrm{K}}$. As $E_{\mathrm{K}}$ was shifted from $-70 \mathrm{mV}$ to $-110 \mathrm{mV}$, the membrane potentials at which inward rectification was observed showed a corresponding shift in the hyperpolarizing direction (Fig. $3 B$ ). The plots also showed that as $E_{\mathrm{K}}$ was set to more hyperpolarized potentials, the resting membrane potential ( () current level) became more hyperpolarized, consistent with the dependence of the resting potential on $I_{\mathrm{Kir}}$. Moreover, the $I-V$ curves showed a marked increase in input resistance at membrane potentials near rest as $E_{\mathrm{K}}$ was shifted from $-70 \mathrm{mV}$ to $-110 \mathrm{mV}$. This increase in input resistance resulted from the reduction in the overlap between the activation curves of the inwardly and outwardly rectifying conductances (Fig. $3 A$ ) When $E_{\mathrm{K}}$ was -70 $\mathrm{mV}$, the overlap of the activation curves for the two conductances was substantial, and therefore the total conductance near rest was relatively high. As $E_{\mathrm{K}}$ was set to more hyperpolarized potentials, the magnitude of overlap between the two activation curves became smaller and the total conductance at rest decreased (Fig. 3A). Although the parameters of the outwardly rectifying conductance were held constant, the membrane potentials at which the $I-V$ curves showed outward rectification became more hyperpolarized in conjunction with $E_{\mathrm{K}}$ (Fig. $3 B$ ). This resulted from the increase in driving force $\left(V_{m}-E_{\mathrm{K}}\right)$ of the outwardly rectifying conductance as $E_{\mathrm{K}}$ was set to more negative values.

\section{The resting potential and inward rectification vary with changes in $\mathrm{E}_{\kappa}$}

The minimal model predicts that shifting $E_{\mathrm{K}}$ to more depolarized potentials should produce a corresponding shift in inward rectification of the $I-V$ relationship. In addition, if $I_{\mathrm{Kir}}$ contributes to the resting potential of spiny neurons, then changing $E_{\mathrm{K}}$ to more depolarized potentials should decrease the resting membrane potential of these cells. Although the precise value of $E_{\mathrm{K}}$ could not be calculated in these experiments because $\left[\mathrm{K}^{+}\right]_{i}$ was unknown, the relative effect of altering $E_{\mathrm{K}}$ on the resting potential and inward rectification was tested by varying $\left[\left.\mathrm{K}^{+}\right|_{\text {, }}\right.$ and the concentration of $\mathrm{K}^{+}$in the microelectrode filling solution $\left(\left[\mathrm{K}^{+}\right]_{c}\right)$. Moreover, if spiny cell membranes were selectively permeable to $\mathrm{K}^{+}$at rest, then $E_{\mathrm{K}}$ would be equal to the resting potential and could be determined experimentally. As predicted, increasing $\left[\mathrm{K}^{+}\right]$, reduced the resting membrane potential. When $\left[\mathrm{K}^{+}\right]_{\text {, was }} 1.0 \mathrm{~mm}, 3.0 \mathrm{~mm}$, and $6.0 \mathrm{~mm}$, the average resting membrane potential of spiny neurons was $-105.2 \pm 5.8 \mathrm{mV}(n$ $=6),-83.4 \pm 2.4 \mathrm{mV}(n=7)$, and $-68.2 \pm 2.6 \mathrm{mV}(n=$ 5) (mean $\pm \mathrm{SD})[F(2,16)=106.9, p<0.05]$, respectively (Fig. $4 A$ ). The slope of the line fitted to these points was $47.4 \mathrm{mV}$ per 10 -fold change in $\left[\mathrm{K}^{+}\right]_{\omega}$. Although this slope was close to the slope value of $58 \mathrm{mV}$ predicted by the Nernst equation, the difference indicated that the membranes of spiny neurons were not solely permeable to $\mathrm{K}^{+}$in the range of $\left[\mathrm{K}^{+}\right]_{\text {, }}$ tested. These data are in agreement with the original studies of Baker et al. (1962) examining the relationship between $E_{\mathrm{K}}$ and the resting

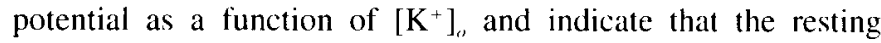
potential of spiny neurons is slightly more depolarized than $E_{\mathrm{K}}$. In this respect, the experimental data differed slightly from the minimal model which for the sake of simplicity was constructed with only two $\mathrm{K}^{+}$currents, and assumed that the resting potential of these cells was equal to $E_{\mathrm{K}}$ (Fig. $3 A$ ). A Cl conductance, which would have an equilibrium potential positive to $F_{\mathrm{K}}$ and would not be blocked by TTX or cadmium. could possibly contribute the resting potential of spiny cells.

In contrast to the effects of increasing $\left[\left.\mathrm{K}^{+}\right|_{1}\right.$, the Nernst equation predicts that increasing $\left[\mathrm{K}^{+}\right]_{i}$ should shift both $E_{\mathrm{K}}$ and thus the resting potential to more hyperpolarized values. Indeed, when $\left[\mathrm{K}^{+}\right]_{i}$ was increased by elevating $\left[\mathrm{K}^{+}\right]_{\text {, in the form of }}$ potassium acetate, the resting potential became more hyperpolarized (Fig. 4B). For separate groups of neurons, when $\left[\mathrm{K}^{+}\right]$. was either $1 \mathrm{M}, 2 \mathrm{M}, 3 \mathrm{M}$, or $4 \mathrm{M}$, the average resting potential of spiny neurons was $-77.5 \pm 4.5 \mathrm{mV}(n=20),-83.8 \pm 2.2$ $\mathrm{mV}(n=40),-89.6 \pm 3.6 \mathrm{mV}(n=5)$, and $-94.0 \pm 2.1 \mathrm{mV}$ $(n=5)[F(3,69)=49.8, p<0.05]$, respectively (Fig. $4 B)$.

In order to study the effect of varying $\left|\mathrm{K}^{\prime}\right|_{\text {, }}$, on inward rectification evoked by hyperpolarization, constant current was injected into cells to maintain the resting potential at a constant value during all conditions. The results showed that increasing $\left[\mathrm{K}^{+}\right.$, from $1 \mathrm{~mm}$ to $6 \mathrm{~mm}$, thereby making $E_{\mathrm{K}}$ more depolarized, produced a decrease in the membrane potentials at which inward rectification was observed (Fig. 4C,D). In contrast, outward rectification, which was expected to be primarily voltage dependent, remained relatively constant. The minimal model predicted that as $E_{\mathrm{K}}$ was set to more hyperpolarized potentials and the activation curves for inwardly and outwardly rectifying conductances diverged, the input resistance of spiny neurons near rest (or $E_{\mathrm{K}}$ ) should increase (Fig. $3 A, B$ ). Consistent with the model, the input resistance of spiny neurons did increase near rest as $E_{\mathrm{K}}$ was hyperpolarized by reducing $\left[\mathrm{K}^{\prime}\right]_{\text {, }}$ (Fig. $4 C . D$ ). It should be noted however, that the increase in input resistance was most apparent in response to small hyperpolarizing pulses (Fig. 4D), whereas in the model the increase in input resistance was most prominent in response to small depolarizing pulses (Fig. 3B). This discrepancy reflected the simplification of the model, which assumed that the resting potential was equal to $E_{\mathrm{K}}$. As shown above, the experimental data indicated that the resting potential was slightly depolarized from $E_{\mathrm{K}}$ (Fig. 4A).

When $E_{\mathrm{K}}$ was hyperpolarized by increasing $\left[\mathrm{K} \cdot l_{\text {, through el- }}\right.$ evations in $\left[\mathrm{K}^{+}\right]_{t}$, inward rectification shifted toward more hyperpolarized membrane potentials (Fig. 4E). Because the shift in the resting membrane potential was not offset by constant current, a corresponding shift in outward rectification was seen similar to that observed in the minimal model. As stated above, this effect most likely reflected the change in driving force of the outwardly rectifying current(s). In contrast to the model, however, outward rectification of the $I-V$ plots in increasing $\left[\mathrm{K}^{+}\right]$, showed similar levels of saturation in the responses to the most depolarizing current pulses. This discrepancy probably reflects the fact that spiny cells have several outward $K$ c currents with different thresholds for activation. Thus, as $E_{\mathrm{K}}$ and the resting potential are depolarized in spiny cells, the magnitude of lower threshold $\mathrm{K}$ ' currents will be reduced, but other outward $\mathrm{K}+$ currents with more depolarized activation thresholds will still 

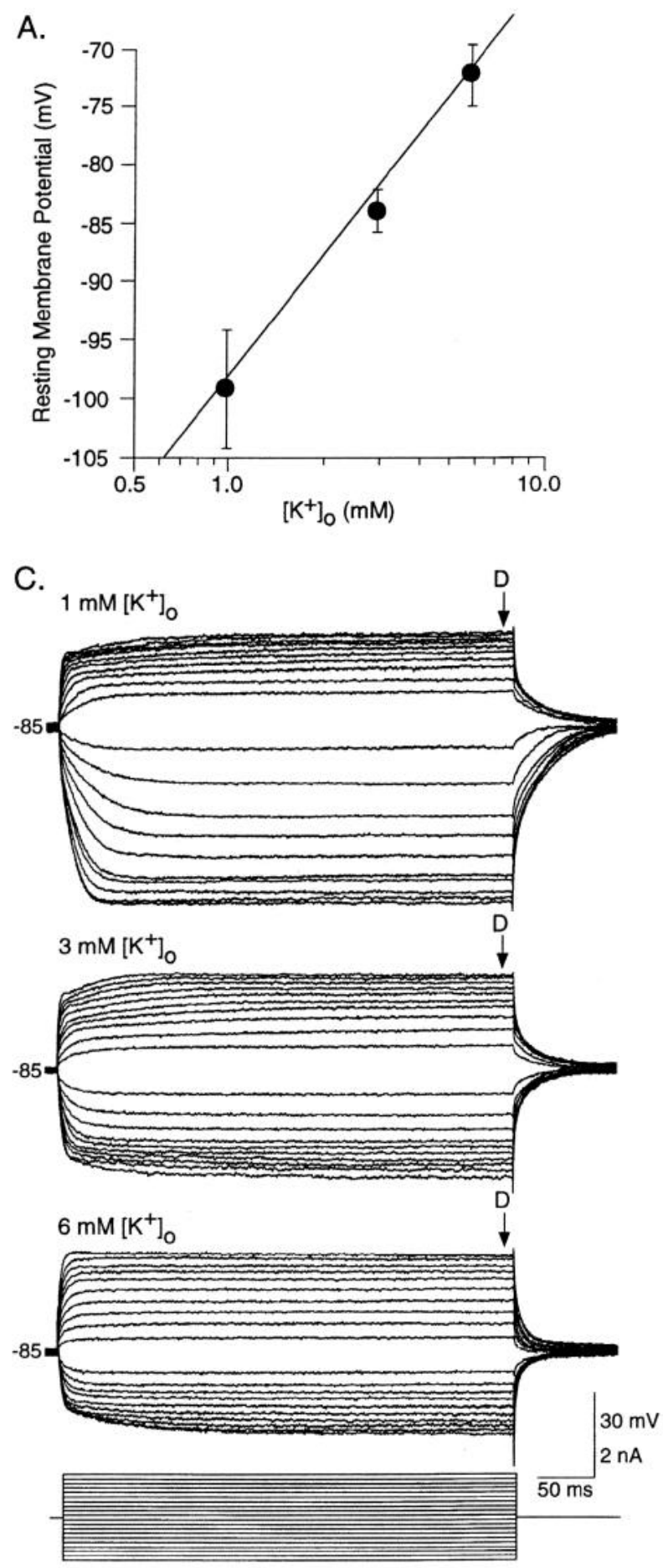

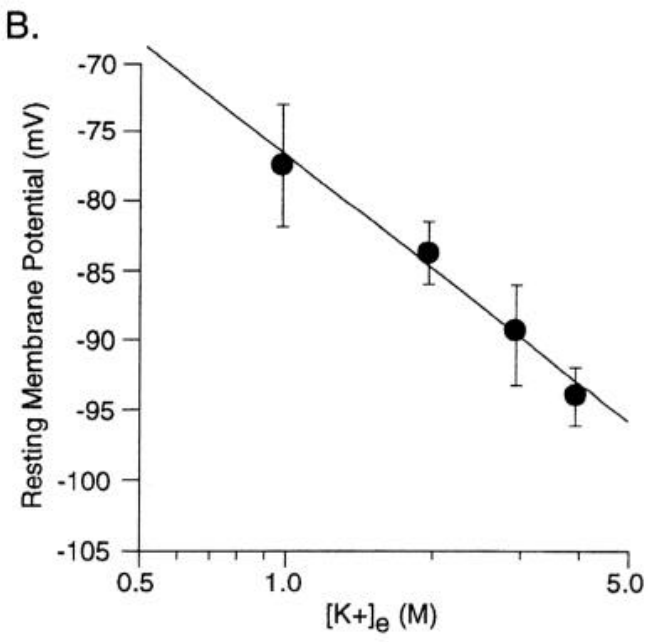

D.

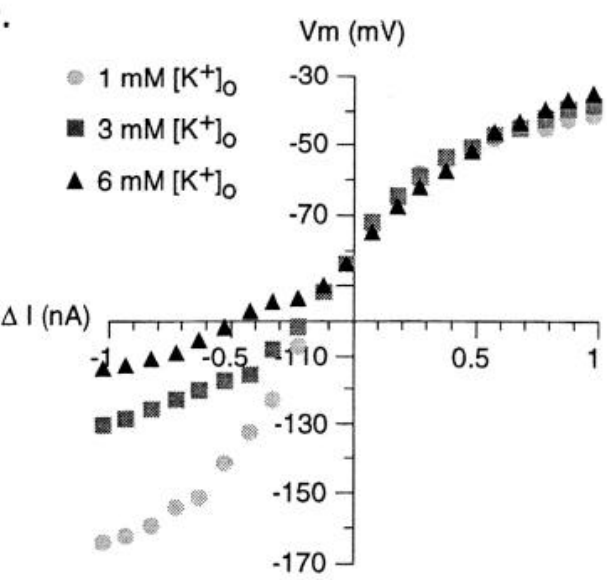

E.

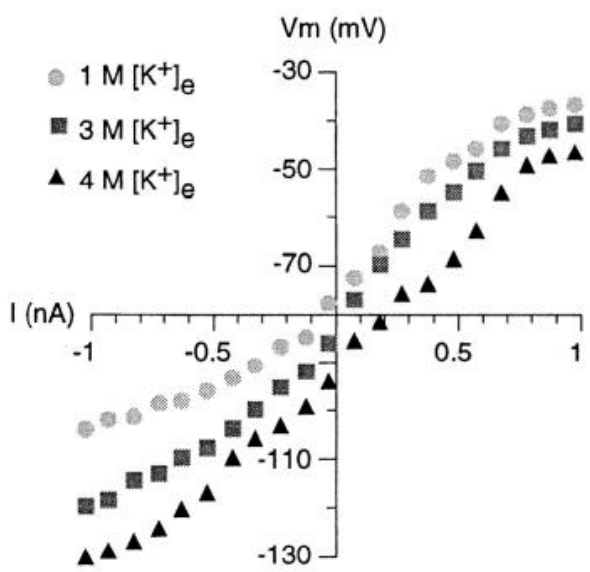

Figure 4. Effects of varying $\left[\mathrm{K}^{+}\right]_{o}$ and $\left[\mathrm{K}^{+}\right]_{i}$ on the $I-V$ responses of neostriatal spiny neurons. $A$, The average resting membrane potential of spiny neurons recorded in the presence of $1 \mathrm{~mm}, 3 \mathrm{mM}$, and $6 \mathrm{~mm}\left[\mathrm{~K}^{+}\right]_{o}$ was $-105.2 \pm 5.8 \mathrm{mV}(n=6),-83.4 \pm 2.4 \mathrm{mV}(n=7)$, and -68.2 $\pm 2.6 \mathrm{mV}(n=5)$, respectively. $B$, When $\left[\mathrm{K}^{+}\right]_{i}$, was varied by changing $\left[\mathrm{K}^{+}\right]_{c}$, the average resting membrane potentials of spiny neurons recorded using electrodes filled with $1 \mathrm{~mm}, 2 \mathrm{mM}, 3 \mathrm{mM}$, and $4 \mathrm{M}$ potassium acetate were $-77.5 \pm 4.5 \mathrm{mV}(n=20),-83.8 \pm 2.2 \mathrm{mV}(n=40),-89.6$ $\pm 3.6 \mathrm{mV}(n=5)$, and $-94.0 \pm 2.1 \mathrm{mV}(n=5)$, respectively. $C$, Responses of a spiny neuron to hyperpolarizing and depolarizing $(-1.0$ to 1.0 $\mathrm{nA}$ ) current pulses $\left(400 \mathrm{msec}\right.$ in duration) in the presence of $1 \mathrm{~mm}, 3 \mathrm{~mm}$, and $6 \mathrm{~mm}\left[\mathrm{~K}^{+}\right]_{o}$ are shown. Constant current was injected into the cell to maintain the resting potential at $-85 \mathrm{mV}$ during all conditions. Consistent with the hypothesis that inward rectification depends on $E_{\mathrm{K}}$, the results showed that as $\left[\mathrm{K}^{+}\right]_{o}$ was increased and $E_{\mathrm{K}}$ became more depolarized, the membrane potentials at which inward rectification was observed decreased. $D$. The $I-V$ plot reflects the membrane potentials evoked by the corresponding current pulse at the time point indicated in $C$. Note that inward rectification shifted toward more depolarized potentials as $\left[\mathrm{K}^{+}\right]_{o}$ was increased from $1 \mathrm{~mm}$ (gray circles) to 3 mм (gray squares) and 6 mм (black triangles). Outward rectification, which is predicted to be primarily voltage dependent, remained relatively constant. $E$, The $I-V$ plots for three different neurons recorded using electrodes filled with $1 \mathrm{~mm}$ (gray circles), $3 \mathrm{~mm}$ (gray squares) and 4 м (black triangles) potassium acetate. Increasing $\left[\mathrm{K}^{+}\right]_{i}$ produced a hyperpolarization of the resting membrane potential, as well as the membrane potential at which inward rectification was observed. 
A. control: $\mathrm{Vm}=-80$

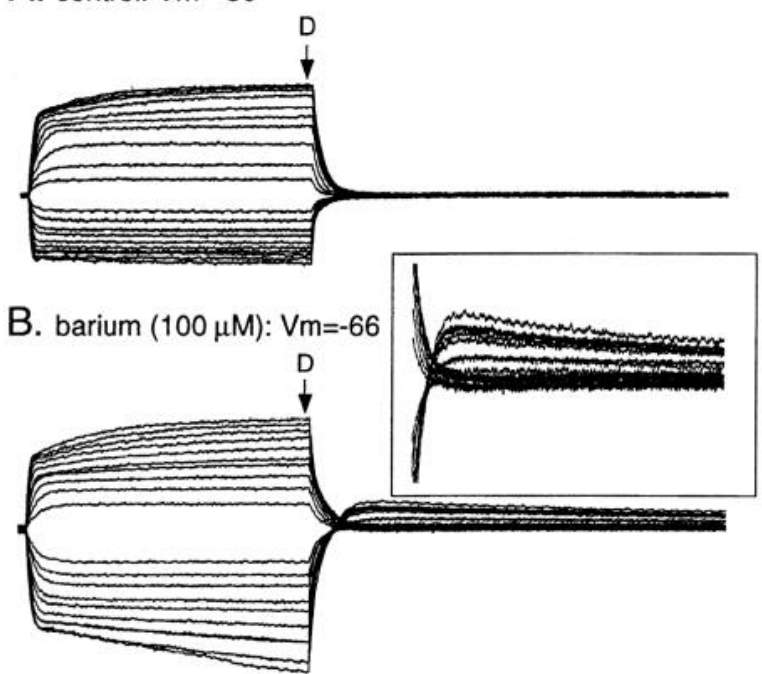

C. barium $(100 \mu \mathrm{M}): \mathrm{Vm}=-80$

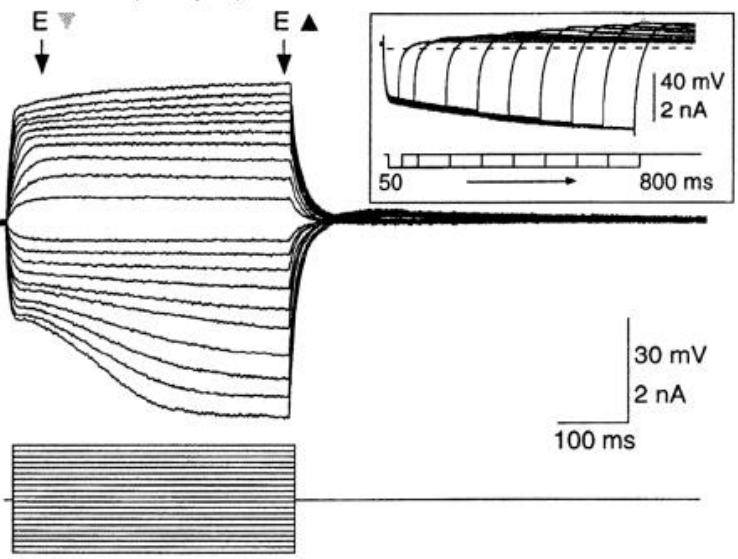

D.

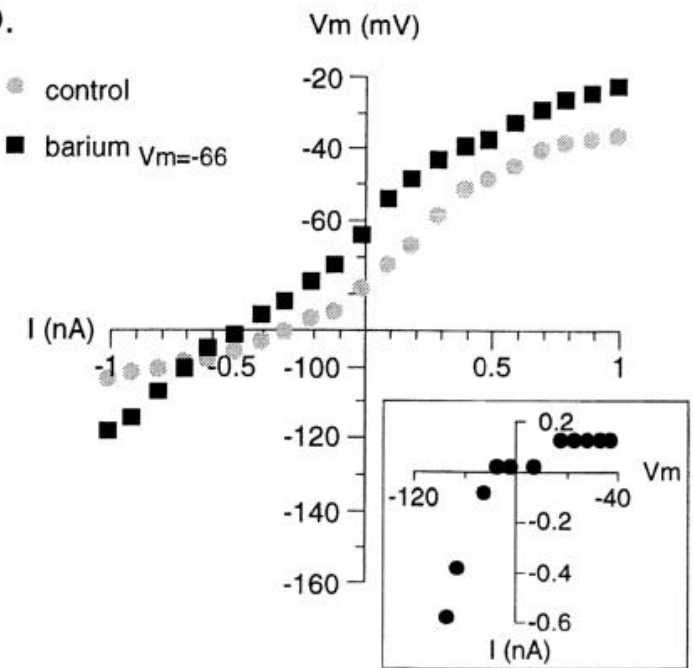

E.

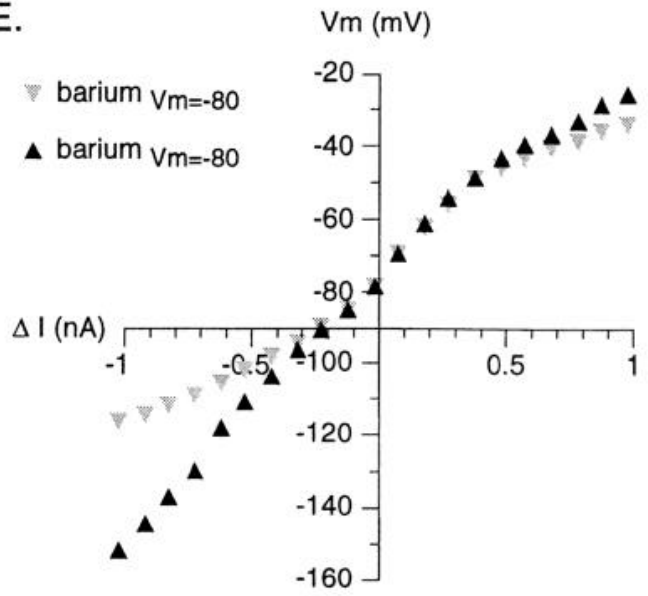

Figure 5. Barium partially blocks inward rectification of neostriatal spiny neurons. A, Inward and outward rectification of the spiny cell responses could be observed after blocking $\mathrm{Na}^{+}$and $\mathrm{Ca}^{2+}$ currents with TTX $(1 \mu \mathrm{M})$ and cadmium $(400 \mu \mathrm{M})$, respectively. $B$, Application of $100 \mu \mathrm{M}$ barium depolarized the neuron by $14 \mathrm{mV}$ and reduced the degree of inward rectification in a time-dependent manner. Barium also produced a rebound depolarization at the offset of hyperpolarizing current pulses. The inset shows the rebound depolarization using a higher gain. $C$, When constant current was injected into the cell in order to maintain the resting membrane potential at its original value $(-80 \mathrm{mV})$, the time-dependent effect of barium on inward rectification became more apparent. The inset shows the positive relationship between the length of a constant amplitude ( -0.5 $\mathrm{nA}$ ) hyperpolarizing current pulse and the magnitude of the rebound depolarization. $D$, The $I-V$ plot reflects the membrane potentials evoked by the corresponding current pulse at the time points indicated in $A$ and $B$. The inward rectification observed during control conditions (gray circles) was reduced by barium (black squares) when the responses were measured at the end of the current pulse. Inset, A manual voltage-clamp experiment was conducted by measuring the current required to step the membrane potential from rest $(-80 \mathrm{mV})$ to various hyperpolarized and depolarized potentials during control and barium conditions. The difference current for each step potential was plotted and showed a pronounced rectification in response to hyperpolarizing voltage steps. Barium also had some effect on outward rectification. $E$, The $I-V$ plot reflects the membrane potentials evoked by the corresponding current pulse at the time points indicated in $C$. This comparison demonstrated the time dependence of the barium blockade of inward rectification in spiny neurons. The $I-V$ relationship measured $50 \mathrm{msec}$ after the current pulse onset (gray triangle) still showed some inward rectification, whereas that measure $390 \mathrm{msec}$ after the current pulse onset (black triangle) was nearly linear in response to hyperpolarization.

be available to limit the amplitude of responses to depolarizing current pulses.

\section{Barium reduces the resting potential and inward rectification}

The results described above suggest that $I_{\mathrm{Kir}}$ contributes to both the resting potential and the inward rectification in the hyperpolarizing direction of the $I-V$ relationship of spiny neurons. Consistent with this hypothesis, application of a low concentration of barium $(100 \mu \mathrm{M})$, which blocks $I_{\mathrm{Kir}}$ (Hagiwara et al., 1978; Standen and Stanfield, 1978; Uchimura et al., 1989), produced a depolarization of spiny neurons from $-84.5 \pm 2.3 \mathrm{mV}$ $(n=25)$ to $-67.7 \pm 5.5 \mathrm{mV}(n=17)(t=13.7, p<0.05)$ (Fig. 5A,B). Barium also reduced the magnitude of inward rectification; however, the effect was time dependent. A continuous increase in input resistance was observed during the course of hyperpolarizing current pulses, and the reduction in inward rectification was most evident at the end of the voltage transients (Fig. 5A,B). The effect of barium also appeared to be voltage dependent. When the resting membrane potential was hyperpolarized to its original value, the continuous increase in input resistance became more apparent (Fig. $5 C$ ). Barium reduced the magnitude of outward rectification, suggesting that this concen- 
tration of barium also had some effect on outward $\mathrm{K}$ ' currents (compare Fig. 5A,C). A rebound depolarization at the offset of hyperpolarizing current pulses also was observed after application of barium (Fig. $5 B$ ). The magnitude of the rebound depolarization was correlated with the degree of hyperpolarization produced by the current pulse. This effect is readily apparent when the offset responses to constant duration (400 msec) current pulses of increasing amplitude $(0.1-1.0 \mathrm{nA})$ are shown at higher gain (Fig. 5B, inset). A similar relationship was found between the duration $(50-800 \mathrm{msec})$ of a constant amplitude $(-0.5 \mathrm{nA})$ hyperpolarizing current pulse and the magnitude of the rebound depolarization (Fig. $5 C$, inset).

The time-dependent effect of barium on inward rectification was apparent in the $I-V$ relationship. When the membrane potentials at the end of the voltage deflections were plotted before and after application of barium, the $I-V$ relationship was nearly linear in the hyperpolarizing direction (Fig 5D). In contrast, when the $I-V$ relationship of spiny neurons was measured at the beginning of the voltage transients, some inward rectification persisted (Fig. 5E). Coupled with the reduction in inward rectification, barium increased the average input resistance of spiny neurons from $38.1 \pm 13.7 \mathrm{M} \Omega(n=12)$ to $56.2 \pm 9.3 \mathrm{M} \Omega(n$ $=17)(t=4.3, p<9.05)$.

$\Lambda$ manual voltage clamp experiment was conducted by measuring the current required to step the membrane potential from rest $(-80 \mathrm{mV})$ to various hyperpolarized and depolarized potentials during control and barium conditions. The difference current was plotted as a function of step potential and showed a pronounced rectification in response to hyperpolarizing voltage steps (Fig. 5D, inset). At the resting potential and in response to small depolarizations, the difference current was negligiblc. However, a small difference current was evident at voltages more depolarized than $-70 \mathrm{mV}$, further supporting the hypothesis that barium had a limited effect on outward $\mathrm{K}$ 'currents (Fig. 5D, inset).

\section{Cesium and TEA block the barium-induced effects on inward rectification}

One explanation for the time-dependent reduction in inward rectification and the rebound depolarization is that these effects result from the time-dependent blocking and unblocking action of barium on $I_{\text {Kir }}$ (Hagiwara et al., 1978; Standen and Stanfield, 1978; Uchimura et al., 1989). An alternative hypothesis is that the time-dependent reduction in inward rectification and the rebound depolarization are due to two different mechanisms. A similar rebound depolarization has been described in several cell types and depends on deactivation of an inwardly rectifying current termed $I_{\mathrm{H}}$ (and $I_{\mathrm{Q}}$ or $I_{\mathrm{f}}$ ) (Brown and DiFrancesco, 1980; Crepel and Penit-Soria, 1986; Spain et al., 1987). $I_{\mathrm{H}}$ is blocked by cesium ( $3 \mathrm{~mm}$; Crepel and Penit-Soria, 1986), but unlike $I_{\mathrm{Kir}}$, $I_{\mathrm{H}}$ is very resistant to TEA even at concentrations of as high as $90 \mathrm{~mm}$ (Wollmuth and Hille, 1992). Therefore, if the time-dependent reduction in inward rectification were due to the barium block of $I_{\mathrm{Kir}}$ and the rebound depolarization resulted from deactivation of the barium-resistant $I_{\mathrm{H}}$, then both effects should be blocked by cesium, but only the reduction of inward rectification should be sensitive to TEA.

When this hypothesis was tested, application of cesium (3 $\mathrm{mm}$ ) blocked both the time-dependent reduction in inward rectification and the rebound depolarization (*) as predicted (Fig. $6 B$ ). Cesium also further reduced the resting membrane potential from $-68.5 \pm 3.9 \mathrm{mV}$ to $-58.8 \pm 2.4 \mathrm{mV}(n=6 ; t=5.1, p$
$<0.05)$. The $I-V$ relationship measured early in the responses showed that the residual inward rectification was blocked by cesium (Fig. $6 \mathrm{~B}$ ). The blockade of inward rectification by cesium was coupled with an increase in the input resistance of spiny neurons compared to control values (control $=38.1 \pm 13.7 \mathrm{M} \Omega$ $n=12$; barium + cesium $=62.2 \pm 17.0 \mathrm{M} \Omega n=6 ; t=3.3$, $p<0.05$ ). In addition, the apparent membrane time constant increased after application of cesium compared to control values (control $=8.5 \pm 3.1 \mathrm{msec}, n=12$; barium + cesium $=18.3$ $\pm 6.3 \mathrm{msec}, n=6 ; t=4.5, p<0.05)$. Cesium also shifted the membrane potentials at which outward rectification was observed and eliminated the ramp potential (Fig. 6B,C). In the absence of prior barium treatment, cesium blocked inward rectification of spiny neurons in a time-independent manner and did not produce a rebound depolarization (Fig. 6, inset).

Similar to the effects of cesium, TEA $(25 \mathrm{~mm})$ blocked both the time-dependent reduction in inward rectification and the rebound depolarization (*) produced by barium (Fig. 6D,E). TEA further reduced the resting membrane potential of spiny neurons from that recorded in the presence of barium (barium $=-68.4$ $\pm 5.7 \mathrm{mV}$; cesium + barium $=-53.6 \pm 4.1 \mathrm{mV}(n=5 ; t=$ $24.6, p<0.05$ ). Examination of the $I-V$ relationship measured at an early time point in the voltage transients showed that TEA blocked the inward rectification, which persisted in the presence of barium (Fig. $6 F$ ). As a consequence, both the input resistance (control $=38.1 \pm 13.7 \mathrm{M} \Omega n=12$; barium + TEA $=70.2$ $\pm 14.5 \mathrm{M} \Omega n=5 ; t=4.3, p<0.05)$ and apparent membrane time constant (control $=8.5 \pm 3.1 \mathrm{msec}, n=12$; barium + TEA $=24.4 \pm 3.5 \mathrm{msec}, n=5 ; t=9.3, p<0.05)$ of spiny neurons increased compared to control values. Taken together, the sensitivity of the rebound depolarization to both cesium and TEA indicate that $I_{\mathrm{H}}$ is not responsible for this response. Consistent with this conclusion, the decrease in amplitude of the rebound depolarization observed when the holding potential was made more hyperpolarized (compare Fig. $5 B, C$ ) suggests that the reversal potential for this response is closer to $E_{\mathrm{K}}$ than to the equilibrium potential for $I_{\mathrm{H}}(\sim-45 \mathrm{mV})$ (Crepel and PenitSoria, 1986; McCormick and Pape, 1990). In addition, the timedependent depolarizing "sag" in hyperpolarizing responses normally associated with activation of $I_{11}$ (Crepel and Penit-Soria, 1986; Spain et al., 1987) was not evident in spiny neurons during control conditions, strongly suggesting that these neurons do not possess this current.

TEA also reduced the outward rectification of spiny neurons evoked by depolarizing current pulses. The decrease in outward rectification could be seen as an increase in the input resistance of the $I-V$ relationship at membrane potentials more depolarized than $-40 \mathrm{mV}$ (Fig. $6 F$ ). A transient overshoot in membrane potential evoked by large depolarizing current pulses also became evident (Fig. 6E). A similar transient overshoot in response to large depolarizing current pulses has been observed after application of high concentrations of 4-AP (Nisenbaum et al., 1994b; see below).

\section{4-AP reduces outward rectification}

The minimal model predicts that outward rectification of neostriatal spiny neurons is dependent on a single voltage-dependent, outwardly rectifying conductance. This is, of course, an oversimplification as at least three depolarization-activated $\mathrm{K}^{+}$currents have been identified in spiny neurons (Surmeier et al., 1991; Nisenbaum et al., 1994a). However, in combination, these currents may act like a single current to limit the membrane poten- 


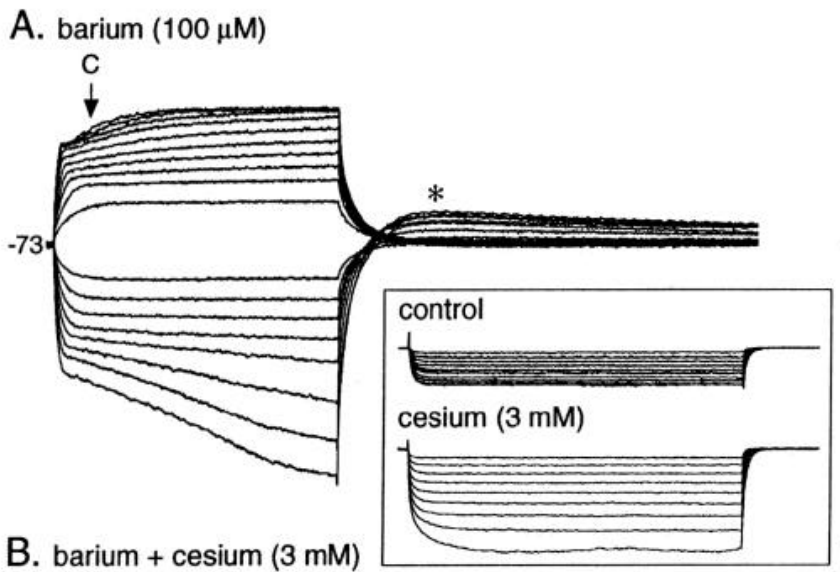

D. barium $(100 \mu \mathrm{M})$

B. barium + cesium $(3 \mathrm{mM})$
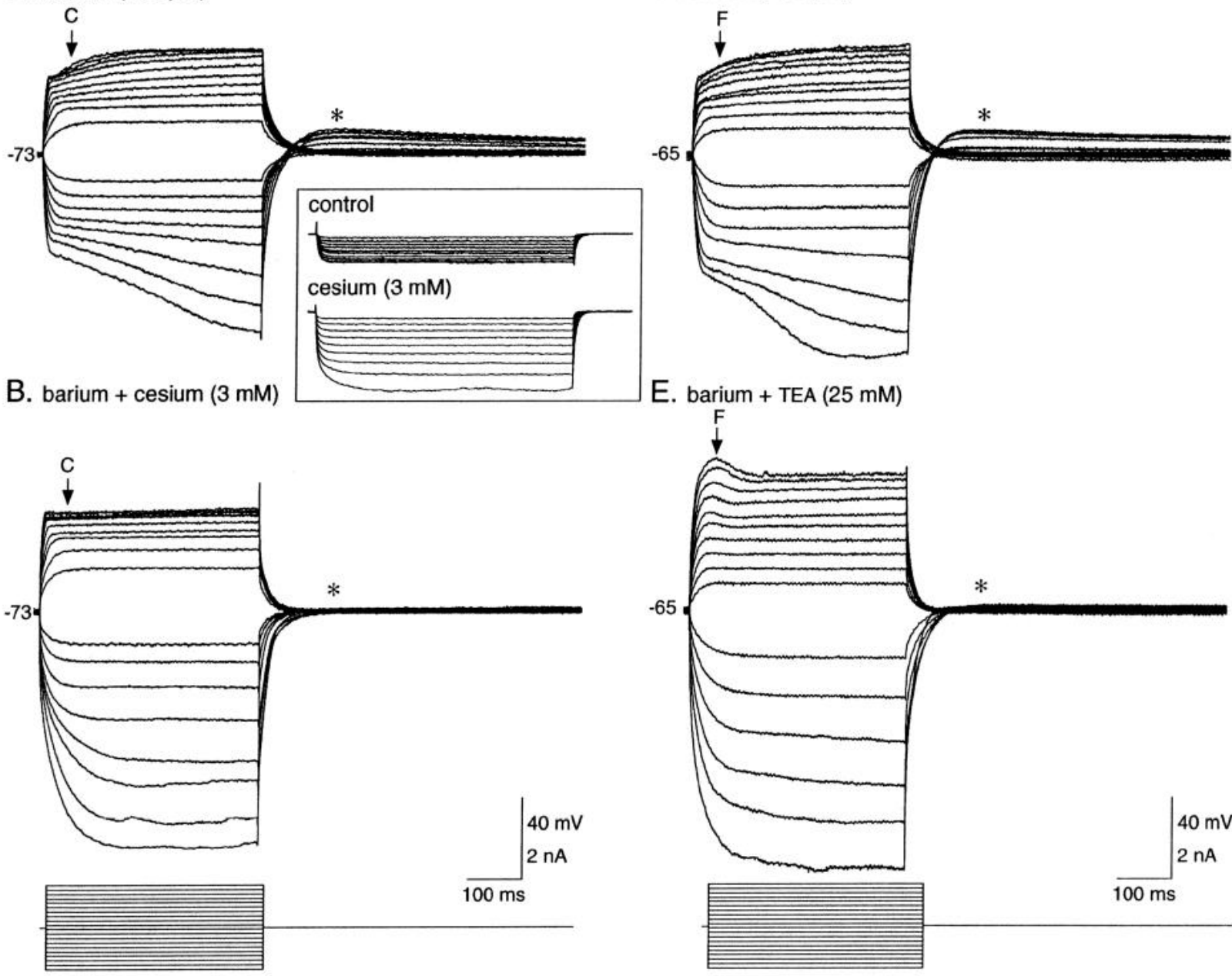

E. barium + TEA $(25 \mathrm{mM})$

C.
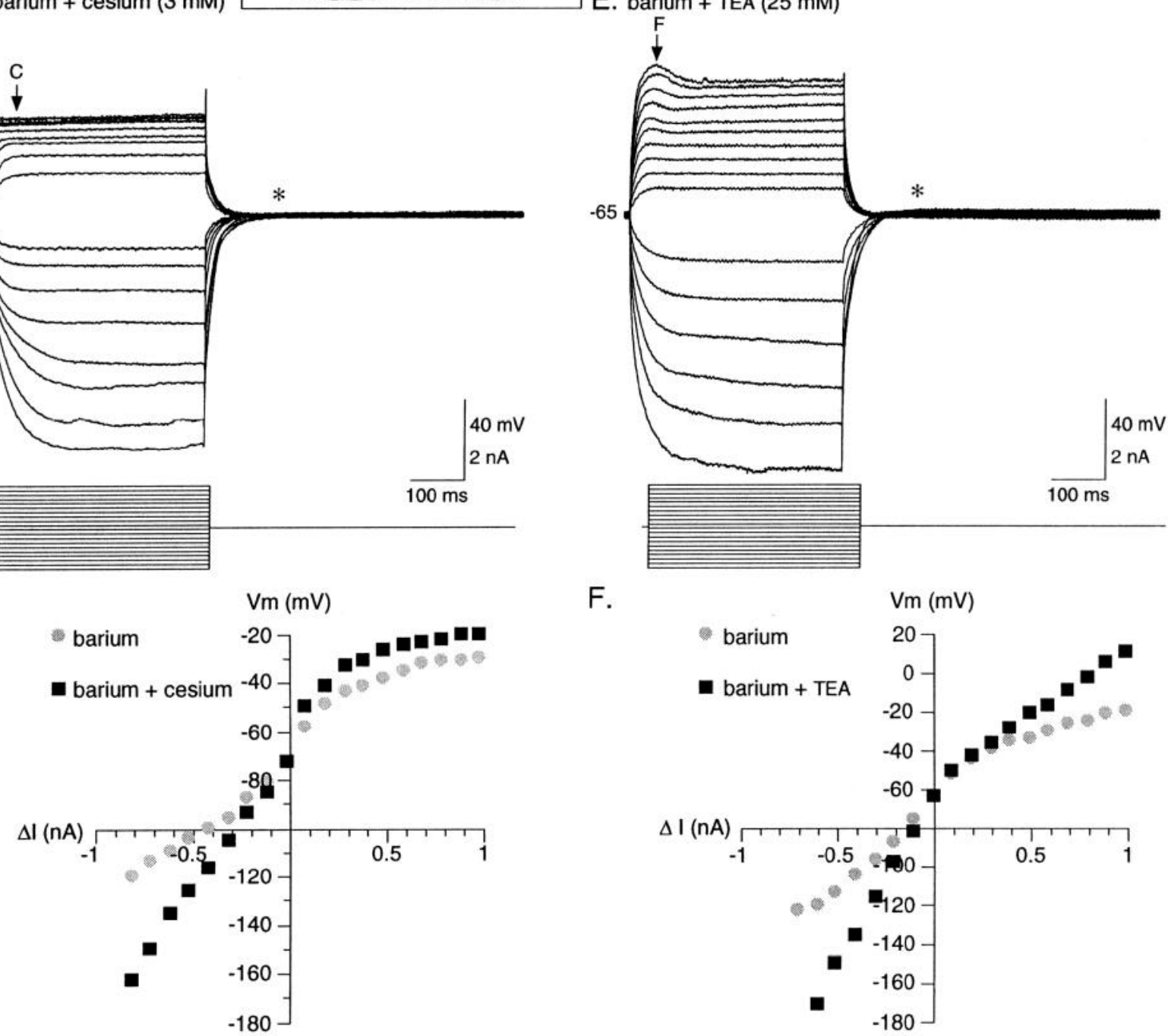

F.

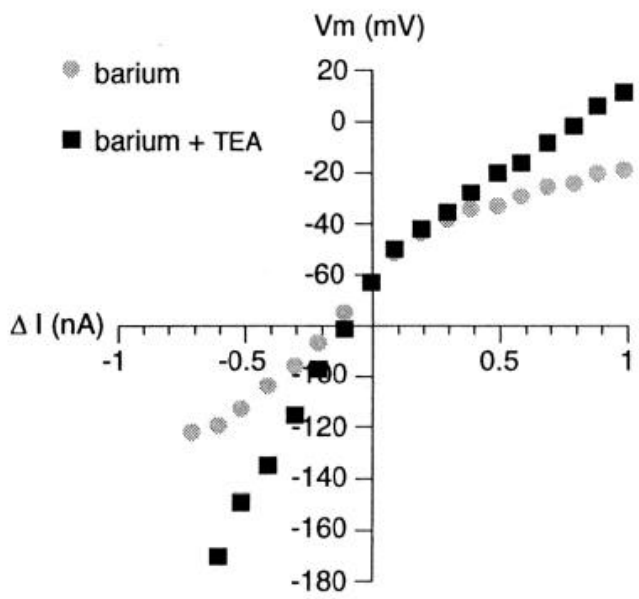

Figure 6. Cesium and TEA block the time-dependent effects of barium on inward rectification of spiny neurons. A, Application of barium (100 $\mu \mathrm{M})$ reduced inward rectification and revealed a rebound depolarization $(*) B$, Subsequent application of cesium $(3 \mathrm{mM})$ blocked the time-dependent effects of barium and the rebound depolarization $(*)$. Inset, Application of cesium alone blocked inward rectification. $C$, The $I-V$ plot reflects the membrane potentials evoked by the corresponding current pulse at the time points indicated in $A$ and $B$. Cesium (black squares) reduced the residual rectification that remained in the presence of barium (gray circles). $D$, In a different neuron, barium ( $100 \mu \mathrm{M})$ produced a time-dependent block of inward rectification, and a rebound depolarization $(*)$. E. Similar to the effects of cesium, subsequent application of TEA (25 mM) blocked the effects of barium. TEA also reduced the outward rectification of spiny neurons evoked by depolarizing current pulses. In the presence of TEA, a transient overshoot in membrane potential was evoked by large depolarizing current pulses. $F$, The $I-V$ plot reflects the membrane potentials evoked by the corresponding current pulse at the time points indicated in $D$ and $E$. TEA (black squares) blocked the residual inward rectification remaining after barium application ( gray circles), and reduced outward rectification. 
A. control

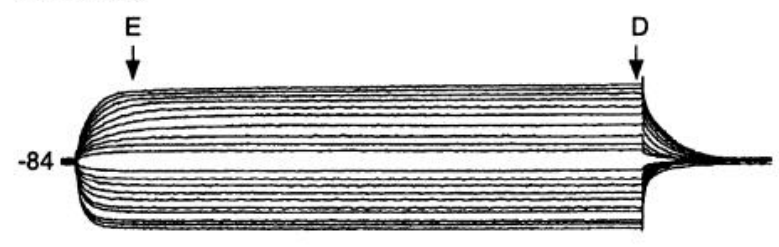

B. 4-AP $(100 \mu \mathrm{M})$

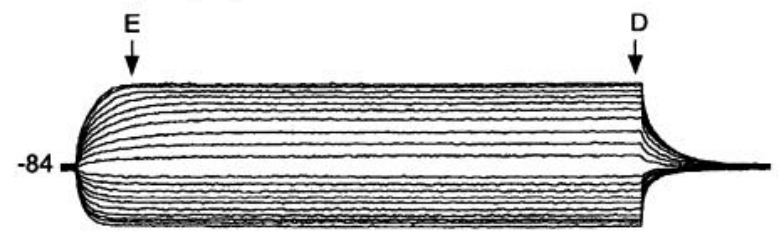

C. 4-AP (2 mM)

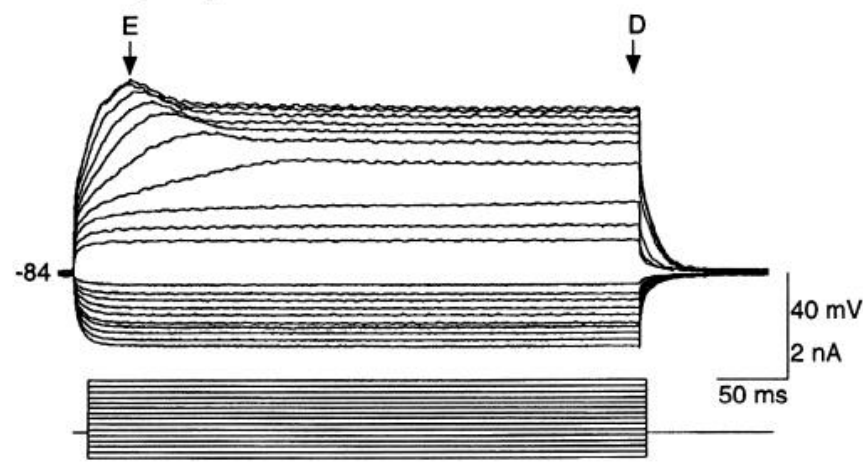

D.

$$
\begin{aligned}
& \text { control } \\
& \text { 4-AP }(100 \mu \mathrm{M}) \\
& \text { 4-AP }(2 \mathrm{mM})
\end{aligned}
$$

$\Delta I(n A)$

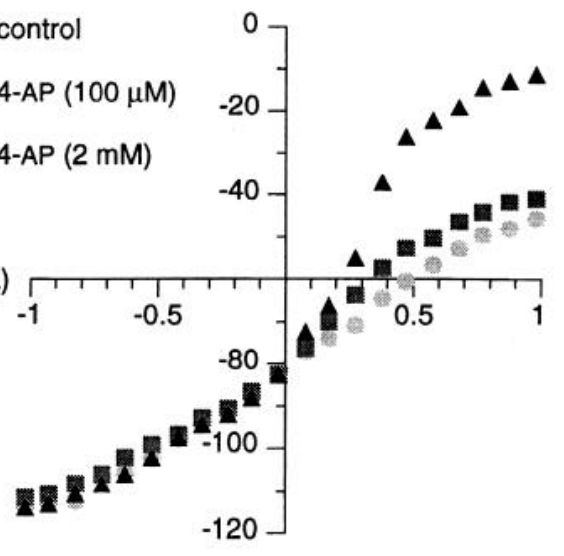

E.

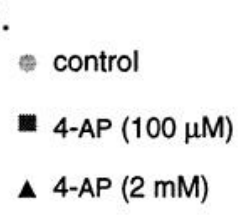

$\Delta \mathrm{I}(\mathrm{nA})$

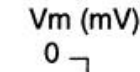

$\mathrm{Vm}(\mathrm{mV})$

$\Delta I(n A)$

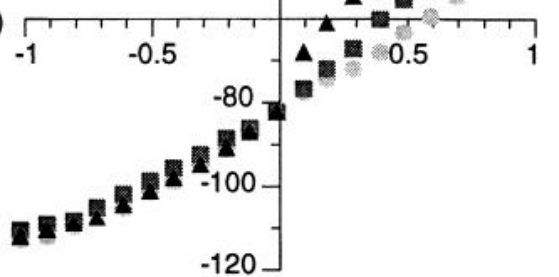

Figure 7. Differential effects of low and high concentrations of 4-AP on the $I-V$ relationship of spiny neurons. $A$, In control media, inward and outward rectification were apparent. $B$, Subsequent application of a low concentration of 4-AP $(100 \mu \mathrm{M})$ increased the input resistance of the cell, but a pronounced outward rectification at approximately $-40 \mathrm{mV}$ persisted. No effect on inward rectification was seen. $C$, When the concentration of 4-AP was increased to $2 \mathrm{mM}$, the membrane rectification early in the pulse was blocked and a transient overshoot in the responses to the largest depolarizing current pulses was observed. $D$ and $E I-V$ plots of the membrane potentials evoked by the corresponding current pulses at the time points indicated in $A-C$. The $I-V$ relationship measured $390 \mathrm{msec}$ after the pulse onset $(D)$ showed that outward rectification observed during control conditions (gray circles) persisted after application of both low (gray squares) and high (black triangles) concentrations of 4-AP. In contrast, measurement of the $I-V$ relationship $50 \mathrm{msec}$ after the pulse onset $(E)$ revealed that outward rectification observed during control conditions ( $g r a y$ circles) was reduced after application of $100 \mu \mathrm{M}$ (gray squares) $2 \mathrm{mM}$ (black triangles) 4-AP.

tial in response to depolarization. By taking advantage of their differential sensitivities to 4-AP and TEA, the contribution of $I_{\mathrm{Af}}, I_{\mathrm{As}}$, and the noninactivating $\mathrm{K}^{+}$current to outward rectification of spiny neurons was investigated. Application of a low concentration of 4-AP $(100 \mu \mathrm{M})$, which selectively blocks $I_{\text {As }}$ (Surmeier et al., 1994), reduced the magnitude of outward rectification (Fig. $7 B, D$ ). This effect was expressed as an increase in input resistance in response to larger depolarizing current pulses $(0.5 \mathrm{nA})$ from $37.5 \pm 8.5 \mathrm{M} \Omega$ to $50.5 \pm 11.7 \mathrm{M} \Omega(n$ $=7 ; t=13.5, p<0.05$ ). After adding 4-AP, a prominent outward rectification of the $I-V$ relationship persisted at potentials less than $-45 \mathrm{mV}$ (Fig. $7 D$ ). When a higher concentration of 4-AP $(2 \mathrm{mM})$, which blocks both $I_{\mathrm{Ar}}$ and $I_{\mathrm{As}}$ (Surmeier et al., 1994), was applied, a portion of the membrane rectification was abolished, revealing a transient overshoot in the responses to the largest depolarizing current pulses (Fig. $7 C$ ). The $I-V$ relationship measured early in the responses showed a considerable increase in input resistance (Fig. $7 E$ ). This high concentration of 4-AP also reduced the degree of outward rectification when measured at the end of the responses (Fig. $7 C, D$ ). However, outward rectification remained at membrane potentials near $-10 \mathrm{mV}$
(Fig. 7D). This residual rectification was evident as a decrease in the amplitude of the voltage transients over time (Fig. $7 C$ ). Neither low nor high concentrations of 4-AP affected the inward rectification of the $I-V$ relationship.

\section{TEA blocks the 4-AP-induced transient overshoot}

The transient overshoot in membrane potential could be due to either a depolarizing hump produced by an inward current or a hyperpolarizing sag resulting from an outward $\mathrm{K}^{+}$current. An inward current having voltage-dependent and kinetic properties consistent with the transient overshoot is the low voltage-activated T-type $\mathrm{Ca}^{2+}$ current (Tsien et al., 1988). However, conflicting results have been reported concerning the presence of T-type $\mathrm{Ca}^{2+}$ currents in neostriatal spiny neurons (Hoehn et al., 1993; Bargas et al., 1994). Moreover, a contribution from a T-type $\mathrm{Ca}^{2+}$ current seems unlikely, given that the overshoot was observed in the presence of $400 \mu \mathrm{M}$ cadmium, which blocks all $\mathrm{Ca}^{2+}$ currents in neostriatal neurons (Bargas et al., 1994). With respect to the latter hypothesis, the noninactivating $\mathrm{K}^{+}$current is a likely candidate to account for the hyperpolarizing sag in membrane potential because it activates slowly at depolarized 


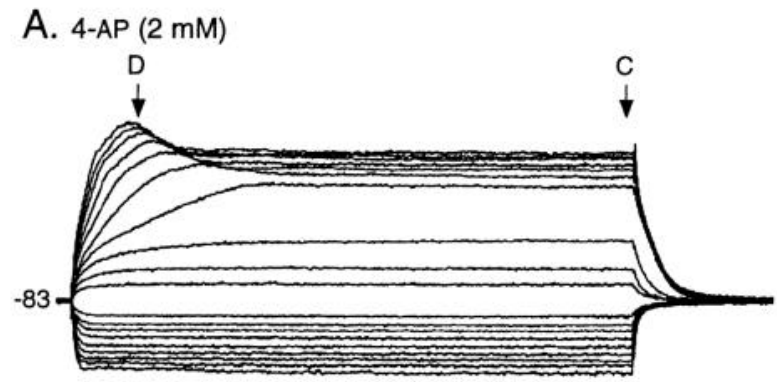

B. 4-AP + TEA (25 mM)

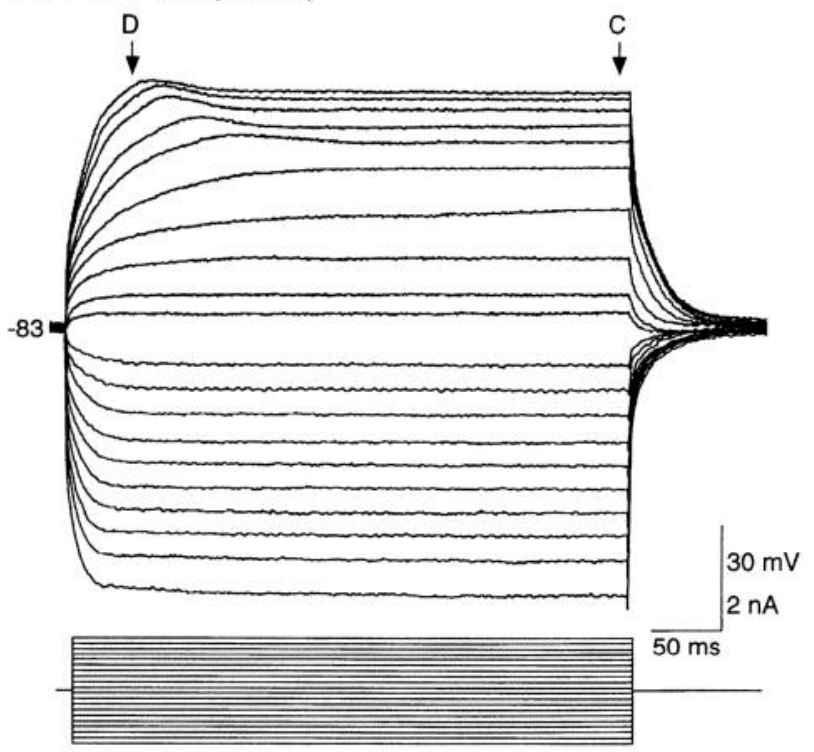

C.

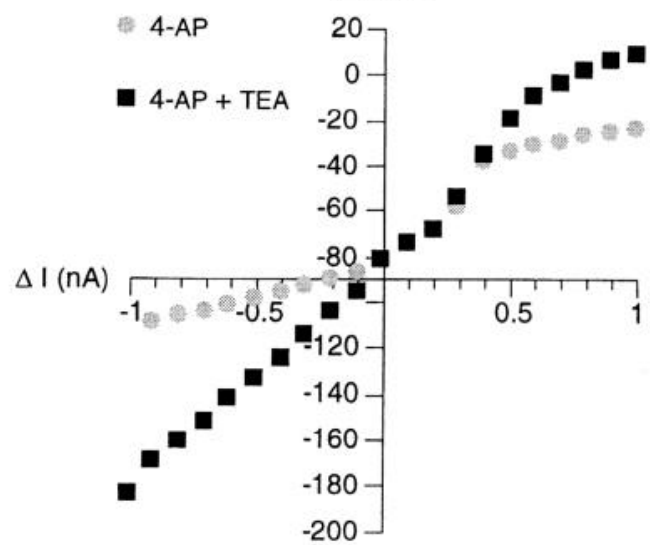

D.

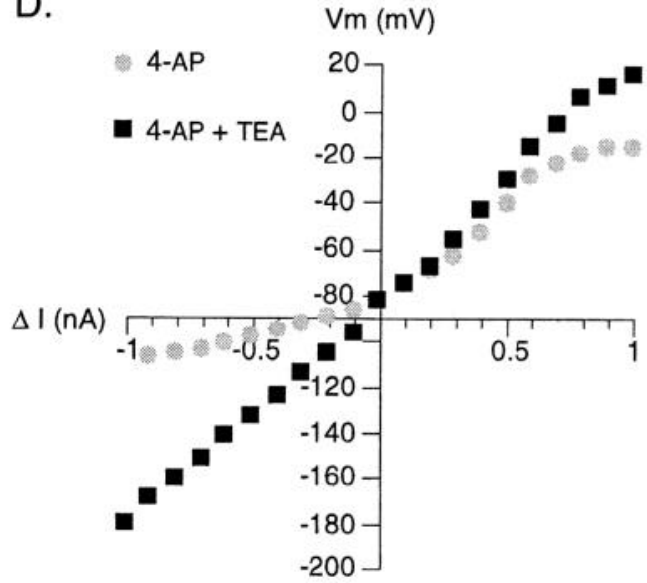

Figure 8. TEA reduces the outward rectification of neostriatal spiny neurons. A, In the presence of 2 mM 4-AP, large depolarizing current pulses $(>0.5 \mathrm{nA}$ ) elicited a transient overshoot in membrane potential. Spiny neurons still displayed pronounced inward rectification. This cell was hyperpolarized with constant current in order to offset the steady-state depolarizing effects of 4-AP. B, Subsequent application of TEA (25 mM) markedly reduced the outward rectification of the responses measured at the end of the current pulse and reduced the magnitude of the transient overshoot. $C$ and $D$ Plots of the membrane potentials evoked by the corresponding current pulses at the time points indicated in $A$ and $B$. The $I-$ $V$ relationship measured $390 \mathrm{msec}$ after the pulse onset $(C)$ showed that outward rectification observed during control conditions $(\mathrm{gray}$ circles) was reduced after application of TEA (black squares). In addition, measurement of the $I-V$ relationship $50 \mathrm{msec}$ after the pulse onset $(D)$ showed an even greater reduction in outward rectification by TEA (black squares).

potentials and shows little inactivation (Nisenbaum et al., 1994a). This hypothesis was tested by taking advantage of the sensitivity of the noninactivating current to TEA (Nisenbaum et al., 1994a). As shown above, application of 4-AP (2 mM) revealed a transient overshoot in response to large depolarizing current pulses (Fig. 8A). Subsequent administration of TEA (25 $\mathrm{mM}$ ) reduced the degree of outward rectification both early and late in the responses (Fig. $8 B$ ). The $I-V$ relationships measured before and after TEA at early and late time points after the onset of the current pulse demonstrated these effects (Fig. $8 C, D$ ). TEA also blocked inward rectification in the hyperpolarizing direction and depolarized the resting membrane potential of spiny cells from $-76.2 \pm 8.5 \mathrm{mV}$ to $-67.3 \pm 11.8 \mathrm{mV}(n=6 ; t=25.2$, $p<0.05$ ) (Fig. $8 B$ ). In the presence of TEA, the $I-V$ relationship was linear over a wide range of membrane potentials (Fig. 8D).

\section{Discussion}

$\mathrm{I}_{\kappa i r}$ is responsible for inward rectification in spiny neurons One of the defining electrophysiological properties of neostriatal spiny projection neurons is the pronounced rectification of their responses evoked by hyperpolarizing current (Kawaguchi et al., 1989). A similar inward or anomalous rectification has been reported for other cell types in a variety of preparations (Katz, 1949; Kandel and Tauc, 1966; Hagiwara and Takahashi, 1974; Constanti and Galvan, 1983). In these oth॰r cell types, inward rectification is produced by $I_{\text {Kir }}$. Several lines of evidence indicate that $I_{\text {Kir }}$ is responsible for inward rectification in spiny neurons as well. First, the saturation in the amplitude of voltage deflections evoked by hyperpolarizing current pulses of increasing amplitude is consistent with an increase in magnitude of $I_{\mathrm{Kir}}$ with greater hyperpolarization (Hagiwara and Takahashi, 1974). Second, the unique voltage dependence of activation of inward rectification is identical to that of $I_{\mathrm{Kir}}$ (Hagiwara and Yoshii, 1979; Leech and Stanfield, 1981). Third, the short apparent membrane time constant is consistent with the nearly time-independent component of $I_{\mathrm{Kir}}$. Furthermore, the decrease in the time constant as a function of membrane potential is predicted by the voltage dependence of the time constant of activation of $I_{\text {Kir }}$ (Hagiwara et al., 1976; Leech and Stanfield, 1981). Fourth, the persistence of inward rectification throughout the duration of 
the voltage transients is consistent with the relatively noninactivating property of $I_{\mathrm{Kir}}$ (Hagiwara et al., 1976). Finally, the timedependent effect of $100 \mu \mathrm{M}$ barium on the hyperpolarizing voltage transients is predicted by its time-dependent blockade of $I_{\mathrm{Kir}}$. Furthermore. the relatively time-independent block of inward rectification by cesium ( $2 \mathrm{mM})$ and TEA $(25 \mathrm{mM})$ is consistent with their effects on $I_{\mathrm{Kir}}$ at these concentrations (Hagiwara et al., 1976, 1978; Gay and Stanfield, 1977; Standen and Stanfield, 1978; Uchimura et al., 1989). Thus, on the basis of similarities between the properties of inward rectification and $I_{\mathrm{Kir}}$ in terms of their unique voltage dependence of activation, kinetics of activation and inactivation, and sensitivity to several $\mathrm{K}^{+}$channel blockers, it is concluded that $I_{\mathrm{Kir}}$ underlies the inward rectification in the hyperpolarizing direction of neostriatal spiny neurons.

$I_{\mathrm{Kir}}$ has been estimated to account for approximately $50 \%$ of the resting conductance of nucleus accumbens neurons and therefore is predicted to make a major contribution to the resting potential of these cells (Uchimura et al., 1989). The present results showed that manipulations that affected inward rectification and thus $I_{\mathrm{Kir}}$ also altered the resting membrane potential of spiny cells. For example, shifting $E_{\mathrm{K}}$ to hyperpolarized potentials produced a hyperpolarizing shift in inward rectification and a corresponding increase in the resting membrane potential of spiny cells. In addition, when inward rectification was reduced by application of blockers of $I_{\text {kir }}$, the resting potential of spiny neurons was depolarized. These results suggest that $I_{\mathrm{Kir}}$ also is responsible for a substantial portion of the resting conductance of neostriatal spiny neurons.

Although previous studies have reported that barium reduces inward rectification in neostriatal neurons, none have described the time-dependent actions of this blocker (Calabresi et al., 1987a, 1990). The present results clearly demonstrated a steady increase in input resistance in response to hyperpolarizing current pulses and a rebound depolarization associated with the offset of these pulses in the presence of barium. These effects are predicted by the time- and voltage-dependent blocking and unblocking actions of $100 \mu \mathrm{M}$ barium on $I_{\mathrm{Kir}}$ (Hagiwara et al., 1978; Standen and Stanfield, 1978; Uchimura et al., 1989). As the membrane potential begins to hyperpolarize, the voltagedependent block by barium of $I_{\text {Kit }}$ will become grealer, increasing the input resistance leading to further hyperpolarization. The greater efficacy of barium over time will further increase the input resistance during the hyperpolarizing response. In combination, the voltage- and time-dependent actions of barium have a positive feedback effect on $I_{\mathrm{Ki}}$, thereby producing a continuous increase in input resistance in response to hyperpolarization. The rebound depolarization is predicted by the time-dependent unblocking action of barium on $I_{\text {Kir }}$ (Hagiwara et al., 1978). Specifically, this response is produced because the current step associated with offset of the pulse is delivered to a cell that effectively has a much higher input resistance and therefore the membrane potential overshoots the holding potential. As this increased input resistance dissipates at a rate determined by the time constant of recovery from barium blockade $(\sim 1.1 \mathrm{sec}$; Uchimura et al., 1989), the membrane potential slowly returns to baseline.

\section{Do all spiny neurons display inward rectification?}

All previous recordings from identified spiny neurons have shown that these cells display inward rectification in response to hyperpolarizing current pulses (Kawaguchi et al., 1989; Nisenbaum et al., 1994b). Indeed, inward rectification is a property of subtypes of spiny neurons residing in either the patch or matrix compartments of the neostriatum (Kawaguchi et al., 1989). In contrast, other studies have shown considerable variability in the presence of inward rectification in recordings from unidentified neostriatal neurons (Bargas et al., 1989; Twery et al., 1994). Given the preponderance of spiny neurons in the neostriatum, this variability does not likely reflect recordings from different cell types (Kemp and Powell, 1971a). An alternative explanation suggested by the unique voltage dependence of activation of $I_{\mathrm{Kir}}$ is that the value of $E_{\mathrm{K}}$ varied between studies. Differences in $E_{\mathrm{K}}$ produced by variations in $\left[\mathrm{K}^{\prime}\right]$, cannot account for the variability as $\left[\mathrm{K}^{+}\right]$, was between 5 and $6 \mathrm{mM}$ in each of these studies (Bargas et al., 1989; Kawaguchi et al., 1989; Twery et al., 1994; present results). On the other hand, differences in $\left[\mathrm{K}^{+}\right]_{i}$ resulting from differences in $\left[\mathrm{K}^{+}\right]$, could give rise to this variability. In those studies in which inward rectification was not always detected, $\left[\mathrm{K}^{+}\right]$, ranged from 3 to 4 M (potassium acetate) (Bargas et al., 1989; Twery et al.. 1994). As shown in the present study, when $[\mathrm{K} \cdot]$, was raised to $3 \mathrm{M}$ or $4 \mathrm{M}$, inward rectification shifted toward very hyperpolarized potentials (see Fig. $4 E$ ). Therefore, only when large hyperpolarizing current pulses were used in these other studies would the membrane potential have been hyperpolarized sufficiently to reveal inward rectification. An additional contribution to this variability may have come from the normal differences in the extent to which recording electrodes used permitted the high $\left[\mathrm{K}^{+}\right]$, to diffuse into the cell and, consequently, shift $E_{\mathrm{K}}$ and inward rectification toward more hyperpolarized potentials. Thus, the combined effects of differences $\left[\mathrm{K}^{+}\right]_{\text {, }}$ and variability in recording electrodes most likely accounts for the variability in detecting inward rectification within studies and between laboratories.

\section{$\mathrm{I}_{4,} \mathrm{I}_{a, s^{*}}$ and the noninactivating $K^{+}$current contribute to outward rectification in spiny neurons}

The $I-V$ relationship of neostriatal spiny neurons displays a prominent outward rectification at potentials near spike threshold. The contribution of the three depolarization-activated $\mathrm{K}$. currents to outward rectification is predicted to depend on their distinctly different voltage-dependent and kinetic properties (Nisenbaum et al., 1994a; Surmeier et al., 1994). $I_{\text {Ar }}$ is expected to make a transient contribution to outward rectification, which is most evident at membrane potentials above spike threshold ( $-40 \mathrm{mV}$ ). In contrast, $I_{\mathrm{A}}$ and the noninactivating current are predicted to make a persistent contribution to outward rectification at both sub- and suprathreshold membrane potentials. However, the fast activation kinetics of $I_{\mathrm{As}}$ suggest that this current will limit the membrane potential throughout a depolarizing response. In contrast, the slow activation kinetics of the noninactivating $\mathrm{K}$ current indicate that its contribution to outward rectification will be delayed in response to depolarization. These hypotheses were tested using concentrations of $\mathrm{K}$ channel blockers, which selectively reduce these three currents.

Consistent with previous reports (Nisenbaum et al., 1994b), selective reduction of $I_{\mathrm{A}}$ using a low concentration of 4-AP decreased the magnitude of outward rectification at membrane potentials below spike threshold. The limiting effect of $I_{\mathrm{A}}$, was evident throughout the duration of the depolarizing response. Subsequent application of a higher concentration of 4-AP. which completely blocks $I_{\mathrm{A},}$ and reduces $I_{\mathrm{Al}}$, revealed a transient overshoot early in the responses to large depolarizing current pulses near spike threshold. However, outward rectification persisted late in these depolarizing responses. Application of concentra- 
tions of TEA that block the noninactivating current markedly reduced both the transient overshoot and the outward rectification of the late portion of the responses. The increase in amplitude of the early portion of the responses may have reflected an action of TEA on any residual $I_{\mathrm{Af}}$, which was not blocked by 2 mM 4-AP. Support for this hypothesis comes from the data, which showed that in the presence of barium, application of TEA reduced outward rectification and revealed a transient overshoot similar to that observed after $2 \mathrm{~mm} 4-\mathrm{AP}$ (see Fig. 6D$F$ ). Thus, these data indicate that the transient overshoot reflects a hyperpolarizing sag rather than a depolarizing hump in membrane potential. In this context, the initial part of the response to large depolarizing current pulses is enhanced as a result of the increase in input resistance associated with the 4-AP block of $I_{\mathrm{Al}}$ (see Fig. $7 E$ ). However, as the noninactivating $\mathrm{K}$ current slowly begins to flow, the level of depolarization diminishes and is maintained at a reduced potential for the duration of the current pulse.

\section{Inward and outward rectification govern the natural activity of} spiny neurons

The spontaneous activity of neostriatal spiny neurons recorded intracellularly in vivo is characterized by episodes of maintained hyperpolarization followed by similar episodes of depolarization. During the periods of hyperpolarization, the membrane potential remains nearly constant at hyperpolarized potentials $(-80$ to $-95 \mathrm{mV}$ ); whereas during the episodes of depolarization the membrane potential resides just below spike threshold $(-40$ to $55 \mathrm{mV}$ ) (Wilson and Groves, 1981; Wilson, 1992, 1993). The duration of these hyperpolarized and depolarized states can last from a few milliseconds to several seconds. The transitions to the depolarized state depend on synchronous excitatory afferent activity arising from the cortico- and/or thalamostriatal pathways (Wilson et al., 1983). In contrast, the hyperpolarized state reflects the membrane potential in the absence of such input (Wilson, 1993). Once the membrane potential has shifted into the depolarized state, action potential discharges may occur and can have a wide range of latencies to the first spike and irregular firing patterns. Thus, the natural activity of spiny neurons is distinguished by shifts between hyperpolarized and depolarized states as a function of the absence or presence of coordinated excitatory synaptic input (Wilson, 1993).

The $I-V$ relationship of spiny neurons recorded in vitro is dominated by inward rectification produced by $I_{\mathrm{Kir}}$ at membrane potentials corresponding to the hyperpolarized state in vivo, suggesting that the degree of membrane polarization achieved during this state is detcrmined by $I_{\mathrm{Kir}}$. In addition, $I_{\mathrm{Kir}}$ accounts for the relatively low input resistance and short membrane time constant of spiny neurons in this membrane potential region. These effects of $I_{\mathrm{Kir}}$ are predicted to shunt the amplitude of excitatory synaptic inputs that terminates primarily on the spine heads of spiny cell dendrites (Kemp and Powell, 197lb). Recent computer simulations have shown that placement of $I_{\mathrm{Kir}}$ on the dendrites, as well as on the soma is critical for this shunting effect to occur (Wilson, 1992). In addition to decreasing the input resistance and membrane time constant, $I_{\mathrm{Kir}}$ extends the electrotonic length of spiny cell dendrites (Wilson, 1992). In combination, these effects of $I_{\mathrm{Kir}}$ will reduce the efficacy of temporally and/or spatially isolated excitatory input by shunting the local excitatory current and lengthening the effective distance between dendrites and soma. Therefore, asynchronous excitatory potentials will be markedly diminished when recorded at the soma, and will produce little perturbation of the membrane po tential in the hyperpolarized state. However, when a spiny cell receives temporally and/or spatially contiguous excitatory inputs, $I_{\mathrm{Kir}}$ will begin to deactivate. As deactivation occurs, the input resistance and time constant will increase, permitting greater temporal and spatial summation of subsequent excitatory potentials, thereby increasing their potency at the soma. In addition, the shortened dendritic electrotonic length will effectively make the dendrites more compact, allowing distal excitatory inputs to influence the soma. Thus. deactivation of $I_{\mathrm{Kir}}$ will create a positive feedback effect that will amplify the local excitatory synaptic current and drive the somal membrane potential away from the hyperpolarized state and into the depolarized state. At membrane potentials corresponding to the depolarized state in vivo, the $I-V$ relationship of spiny neurons displays a pronounced outward rectification. Once the cell membrane potential has reached the depolarized state, outward rectification is predicted to underlie the relatively constant membrane potential associated with this state. The properties of $I_{\mathrm{A}}$ and the noninactivating $\mathrm{K}^{+}$current make them likely candidates for placing the limits on the amplitude of the depolarizing synaptic barrage. In addition, the slow inactivation kinetics of $I_{\mathrm{A}}$ and the noninactivating current will permit them to exert their influence for the duration of the depolarized state, which can last for several seconds (Wilson and Groves, 1981).

Finally, the spike discharge characteristics of spiny neurons are predicted to depend on all three outward $\mathrm{K}^{+}$currents. Spiny neurons recorded in vivo often display long latencies to initial spike discharge after reaching the depolarized state (Wilson, 1992, 1993). This delay to first spike discharge can be mimicked in vitro in response to intracellular current pulses, and has been shown to depend on activation of $I_{\mathrm{As}}$ (Nisenbaum et al., 1994b). Therefore, $I_{\mathrm{A}}$ probably contributes to the latency to first spike firing of spiny neurons recorded in vivo. However, the slow kinetics of recovery from inactivation of $I_{\mathrm{A}}$ indicate the its influence on the latency to spike discharge will depend on the time the cell has previously spent in the hyperpolarized state before receiving an excitatory synaptic barrage (Surmeier et al., 1992; Nisenbaum et al., 1994b). More specifically, a brief period in the hyperpolarized state will reduce the availability of $I_{\mathrm{A} v}$, permitting the membrane potential to reach spike threshold sooner; whereas an extended period in the hyperpolarized state will increase the availability of $I_{\mathrm{As}}$ and, consequently, prolong the latency to first spike firing. $I_{\mathrm{Al}}$ and the noninactivating current are predicted to influence the firing pattern of spiny neurons by shaping the action potential configuration by dictating the rate of repolarization. $I_{\mathrm{A}}$ also will contribute to the spike afterhyperpolarization (AHP) (Connor and Stevens, 1971). Given that $I_{\mathrm{A}}$ inactivates rapidly and is half-inactivated at potentials near spike threshold ( $-40 \mathrm{mV}$ ) (Surmeier et al., 1991), the contribution of this current should be greatest soon after the cell enters the depolarized state. If the depolarized state is maintained, then the effect of $I_{\mathrm{Ar}}$ on spike AHP should be reduced. Consistent with this hypothesis, the AHP of spiny cells recorded in viro is greatest soon after the onset of a long depolarizing current pulse. and is reduced at the end of the pulse (Kita et al., 1985a; Pineda et al., 1992).

\section{References}

Arbuthnott GW. MacLeod NK. Rutherford A (1985) The rat corticostriatal pathway in vitro. J Physiol (Lond) 367:102p.

Baker PF, Hodgkin AL, Shaw TI (1962) The effects of changes in 
internal ionic concentrations on the electrical properties of perfused giant axons. J Physiol (Lond) 161:355-374.

Bargas J, Galarraga E, Aceves J (1989) An early outward conductance modulates the firing latency and frequency of neostriatal neurons of the ral brail. Exp Brain Res 75:146-156.

Bargas J, Howe A, Eberwine J, Cao Y, Surmeier DJ (1994) Cellular and molecular characterization of $\mathrm{Ca}^{2+}$ currents in acutely-isolated, adult rat neostriatal neurons. J Neurosci 14:6667-6686.

Brown H. DiFrancesco D (1980) Voltage-clamp investigations of membrane currents underlying pace-maker activity in rabbit sino-atrial node. J Physiol (Lond) 308:331-351

Calabresi P, Mercuri NB, Stanzione P, Stefani A, Bernardi G (1987a) Intracellular studies on the dopamine-induced firing inhibition of neostriatal neurons in vitro: evidence for $\mathrm{D}_{1}$ receptor involvement. Neuroscience 20:757-771.

Calabresi P. Misgeld U, Dodt IIU (1987b) Intrinsic membrane properties of neostriatal neurons can account for their low level of spontaneous activity. Neuroscience 20:293-303.

Calabresi P, Mercuri NB, Bernardi G (1990) Synaptic and intrinsic control of membrane excitability of neostriatal neurons. II. An in vitro analysis. J Neurophysiol 63:663-675.

Connor JA, Stevens CF (1971) Voltage clamp studies of a transient outward membrane current $\mathrm{n}$ a gastropod neural somata. J Physiol (I ond) 213:21-30.

Constanti A, Galvan M (1983) A fast inward rectifying current accounts for anomalous rectification in olfactory cortex neurones. $J$ Physiol (Lond) 385:153 178

Crepel F, Penit-Soria J (1986) Inward rectification and low threshold calcium conductance in rat cerebellar purkinje cells. An in vitro study. J Physiol (Lond) 372: 1-23.

Gay LA, Stanfield PR (1977) Cs' causes a voltage-dependent block of inward $\mathrm{K}$ currents in resting skeletal muscle fibers. Nature 267:169 170.

Hagiwara S, Takahashi K (1974) The anomalous rectification and cat ion selectivity of the membrane of starfish egg cell. J Membr Biol 18:61-80.

Hagiwara S, Yoshii M (1979) Effects of internal potassium and sodium on the anomalous rectification of the starfish egg as examined by internal perfusion. J Physiol (Lond) 292:251-265.

Hagiwara S, Miyazaki S, Rosenthal NP (1976) Potassium current and the effect of cesium on this current during anomalous rectification of the egg cell membrane of a starfish. J Gen Physiol 67:621-638.

Hagiwara S, Miyazaki S, Moody W, Patlak J (1978) Blocking effects of barium and hydrogen ions on the potassium current during anomalous rectification in the starfish egg. J Physiol (Lond) 279:167-185.

Hoehn K, Watson TWJ, MacVicar BA (1993) Multiple types of calcium channels in acutely isolated rat neostriatal neurons. J Neurosci 13:1244-1257.

Horikawa K, Armstrong WE (1988) A versatile means of intracellular labeling: injection of biocytin and its detection with avidin conjugates. J Neurosci Methods 25:1-11

Jiang ZG. North RA (1991) Membrane propertics and synaptic responses of rat striatal neurons in vitro. J Physiol (Lond) 443:533553

Kandel ER. Tauc L (1966) Anomalous rectification in the metacerebral giant cells and its consequences for synaptic transmission. J Physiol (Lond) 183:287-304

Katz B (1949) Les constantes electriques de la membrane du muscle. Arch Sci Physiol 3:285.

Kawaguchi Y, Wilson CJ. Emson PC (1989) Intracellular recording of identified neostriatal patch and matrix spiny cells in a slice preparation preserving cortical inputs. J Neurophysiol 62:1052-1068.

Kawaguchi Y, Wilson CJ, Emson PC (1990) Projection subtypes of rat neostriatal matrix cells revealed by intracellular injection of biocytin. J Neurosci 10:3421-34.38.

Kemp JM. Powell TPS (1971a) The structure of the caudate nucleus of the cat: light and electron microscopy. Philos Trans R Soc Lond [Biol] 262:383-401.

Kemp JM, Powell TPS (1971b) The site of termination of afferent fibres in the caudate nucleus. Philos Trans R Soc Lond [Biol] 262: 413-427.

Kita H. Kita T, Kitai ST (1985a) Active membrane properties of rat neostriatal neurons in an in vitro slice preparations. Exp Brain Res $60: 54-62$
Kita H, Kita T, Kitai ST (1985b) Regenerative potentials in rat neostriatal neurons in an in vitro slice preparation. Exp Brain Res 60 .

Kita T, Kita H, Kitai ST (1984) Passive electrical membrane properties of rat neostriatal neurons in an in vitro slice preparation. Brain Res 300:129-139.

Leech CA, Stanfield PR (1981) Inward rectification in frog skeletal muscle fibres and its dependence on membrane potential and external potassium. J Physiol (Lond) 319:295-309.

McCormick DA, Pape H-C (1990) Properties of a hyperpolarizationactivated cation current and its role in rhythmic oscillation in thalamic relay neurones. J Physiol (Lond) 431:291-318

Nisenbaum ES, Grace AA, Berger TW (1988) Pharmacological enhancement of paired impulse inhibition in the in vitro striatum. J Neurosci Methods 24:206.

Nisenbaum ES, Wilson CJ, Surmeier DJ (1994a) Depolarization evokes a slowly-activating $\mathrm{K}^{+}$current in rat striatal neurons. Soc Neurosci Abstr 20:564.

Nisenbaum ES, Xu ZC, Wilson CJ (1994b) Contribution of a slowly. inactivating potassium current to the transition to firing of neostriatal spiny projection neurons. J Neurophysiol 71:1174-1189.

Pineda JC, Galarraga E, Bargas J, Cristancho M, Aceves J (1992) Carybdotoxin and apamin sensitivity of the calcium-dependent repolarization and afterhyperpolarization in neostriatal neurons. J Neurophysiol 68:287-294

Rall W (1977) Core conductor theory and cable properties of neurons. In: Handbook of physiology: cellular biology of neurons (Brookhart JM, Mountcastle VB, Kandel ER, eds), pp 39-97. Bethesda, MD: American Physiological Society.

Spain WJ, Schwindt PC, Crill WE (1987) Anomalous rectification in neurons from cat sensorimotor cortex in vitro. J Neurophysiol 57: $1555-1576$

Standen NB, Stanfield PR (1978) A potential- and time-dependent blockade of inward rectification in frog skeletal muscle fibres by barium and strontium ions. J Physiol (Lond) 280:169-191.

Sugimori M, Preston RJ, Kitai ST (1978) Responses properties and electrical constants of caudate nucleus neurons in the cat. J Neurophysiol 41:1662-1675.

Surmeier DJ, Foehring R, Stefani A, Kitai ST (1991) Developmental expression of a slowly-inactivating voltage dependent potassium current in rat neostriatal neurons. Neurosci Lett 122:41-46.

Surmeier DJ, Eberwine J, Wilson CJ. Stefani A. Kitai ST (1992a) Dopamine receptor subtypes co-localize in acutely-isolated rat striatonigral neurons. Proc Natl Acad Sci USA 89:10178-10182.

Surmeier DJ, Xu ZC, Wilson CJ, Stefani A, Kitai ST (1992b) Grafted neostriatal neurons express a late-developing transient potassium current. Neuroscience 48:849-856.

Surmeier DJ, Wilson CJ, Eberwine J (1994) Patch-clamp techniques for studying potassium currents in mammalian brain neurons. In: Methods in neurosciences: methods for the study of ion channels. pp 39-67. San Diego: Academic.

Tsien RW, Lipscombe D, Madison DV, Bley KR, Fox AP (1988) Multiple types of neuronal calcium channels and their selective modulation. Trends Neurosei 11:431-438.

Twery MJ, Thompson LA, Walters JR (1994) Electrophysiological characterization of rat striatal neurons in vitro following a unilateral lesion of dopamine cells. Synapse 13:322-332.

Uchimura N, Cherubini E, North RA (1989) Inward rectification in rat nucleus accumbens neurons. J Neurophysiol 62:1280-1286.

Wilson CJ (1992) Dendritic morphology, inward rectification, and the functional properties of neostriatal neurons. In: Single neuron computation (McKenna T, Davis J, Zornetzer SF, eds), pp 141-171. San Diego: Academic.

Wilson CJ (1993) The generation of natural firing patterns in neostriatal neurons. In: Progress in brain research (Arbuthnott G, Emson PC, eds), pp 277-297. Amsterdam: Elsevier.

Wilson CJ, Groves PM (1980) Fine structure and synaptic connections of the common spiny neuron of the rat neostriatum: a study employing intracellular injection of horseradish peroxidase. J Comp Neurol 194:599-615.

Wilson CI, Groves PM (1981) Spontaneous firing patterns of identified spiny neurons in the rat neostriatum. Brain Res 220:67-80.

Wilson CJ, Chang HT, Kitai ST (1983) Disfacilitation and long-lasting inhibition of neostriatal neurons in the rat. Exp Brain Res 51:227235.

Wollmuth LP, Hille B (1992) Ionic selectivity of $l_{\text {}}$ channels of rod photorceptors in tiger salamanders. J Gen Physiol 100:749-765. 